aene

Investigaciones de Historia Económica - Economic History Research

Asociación Española de

Historia Económica

Artículo

\title{
La rentabilidad financiera de los grupos económicos chilenos en el largo plazo (1938-1988)
}

\author{
Andrés Aguirre Briones* ID \\ Universitat de Barcelona
}

\section{INFORMACIÓN DEL ARTÍCULO}

\section{Historia del artículo:}

Recibido el 18 de febrero de 2019

Aceptado el 25 de septiembre de 2019

On-line el 1 de abril de 2020

\section{Códigos JEL:}

N00

N66

N86

\section{Palabras clave:}

Rentabilidad financiera

Grupos económicos

Demanda en los mercados

Historia empresarial

\section{JEL classification:}

N00

N66

N86

\section{Keywords:}

ROE

Business groups

Demand in markets

Business history

\section{R E S U M E N}

En este artículo, se realiza un examen de la rentabilidad financiera de los grupos económicos chilenos entre 1938 y 1988. Al ser los grupos empresariales los controladores de las mayores empresas privadas del país, se efectúa un análisis de largo plazo que les sitúa en el escenario económico de la industrialización sustitutiva de importaciones (1939-1973) y el neoliberalismo (1974-1988). Después de analizar la pertinencia de variables como el tamaño de los grupos, las fluctuaciones de precios, shock de costes de energía, la estructura concentrada de la economía y el impuesto a las utilidades, se establece que es el movimiento de la demanda interna y externa de la economía el factor que permite entender la evolución de la rentabilidad de los grupos económicos chilenos en el largo plazo.

(C) 2019 Asociación Española de Historia Económica

\section{The financial profitability of the Chilean economic groups in the long term (1938-1988)}

\section{A B S T R A C T}

In this article, we carry out an examination of the financial profitability of the Chilean economic groups between 1938 and 1988. Being the business groups the controllers of the largest private companies of the country, we made an analysis of long term that puts groups in the economic arena of the import substitution industrialization (1939-1973) and the neoliberalism (1974-1988). After analyzing the relevance of size of groups, the fluctuations of prices, energy shocks, the concentrated structure of the economy and the tax on companies, we determined that the movement of the internal and external demand of the economy is the factor that contribute to understand the evolution of the long term profitability of the Chilean business groups.

(C) 2019 Asociación Española de Historia Económica

\footnotetext{
* Autor para correspondencia.

Correo electrónico: andresaguirreb@hotmail.com (Andrés Aguirre Briones)
} 


\section{Introducción}

En este artículo se examina la rentabilidad financiera de los principales grupos económicos chilenos entre 1938 y $1988^{1}$. Su propósito consiste en conocer las características y establecer los factores que inciden en la evolución de este relevante indicador de desempeño empresarial para los principales grupos económicos del país en el transcurso de la industrialización sustitutiva de importaciones (1938-1973) y el neoliberalismo en el marco del régimen militar (1974-1988). La especificidad de la economía chilena, caracterizada por una aplicación ortodoxa de dichos modelos de política económica, contribuye a entender la rentabilidad de los grupos empresariales en un entorno de rasgos "canónicos» en relación con el contexto latinoamericano ${ }^{2}$.

Los grupos económicos se constituyen, en el largo plazo, como la forma empresarial predominante en $\mathrm{Chile}^{3}$. A partir de lo anterior, este tema de investigación se ha convertido en un campo cada vez más dinámico. En lo fundamental, las aportaciones en esta materia han examinado el papel de las privatizaciones en la expansión de los grupos de empresas durante el esquema de libre mercado; la preferencia por una articulación piramidal de la propiedad; los límites que constituyen a los grupos; los resultados de la afiliación al grupo en comparación con las unidades no afiliadas; la preponderancia de los grupos entre las empresas cotizantes en el mercado bursátil; la gobernanza corporativa; el rol del mercado de capitales, el endeudamiento y su incidencia en los grupos; la persistencia de la estructura piramidal y el creciente nivel de diversificación; la composición, densidad y consecuencias de la red de directorios entrelazados en el largo plazo, y los orígenes de los grupos económicos ${ }^{4}$. Respecto al estudio de la rentabilidad empresarial en el contexto latinoamericano, las escasas contribuciones en esta materia se remontan a Brandenburg (1964), quien considera la rentabilidad financiera de grandes empresas del subcontinente. Cuesta y Newland (2015) indagan en la rentabilidad de grandes

\footnotetext{
${ }^{1}$ Los grupos empresariales se organizan como una estructura de control y coordinación de empresas que operan en diferentes mercados. Acerca de los grupos económicos, el modelo de empresa prevaleciente en América Latina, Asia y en determinados países europeos, véase Colpan y Hikino (2016); Fernández et al. (2015); Guillén (2001), y Amsden (2001). La rentabilidad financiera consiste en la ratio entre los beneficios netos divididos por el capital y reservas (recursos propios). La rentabilidad financiera es también conocida como return on equity (ROE). Otras medidas de la rentabilidad se remiten al cálculo de las utilidades sobre activos, denominada rentabilidad económica o return on assets (ROA), o la rentabilidad sobre la inversión, return on investment (ROI). Se exploró la posibilidad de combinar el examen de la rentabilidad financiera junto a la emanada de los activos. No obstante, esta opción se mostró inviable por la inexistencia de datos suficientes que posibiliten una medición amplia y consistente en el largo plazo, debido a la discontinuidad de las memorias y balances de las empresas que componen grupos económicos a partir de la información recabada en la Superintendencia de Valores y Seguros, Archivo de la Administración y Biblioteca Nacional de Chile.

2 Véase Bértola y Ocampo (2013); Astorga et al. (2005), y Thorp (1998).

3 Véase, Fernández y Lluch (2015); Fazio (2005, 2000); Sapelli (2002); Paredes y Sánchez (1996); Sanfuentes (1984); Garretón y Cisternas (1970), y Lagos (1960).

${ }^{4}$ Véase, respectivamente, Ross Schneider (2013); Fernández Gilberto (2000); Fazio (1997); Montero (1997); Marín y Rozas (1988); Dahse (1979); Fuentes (1997); Khanna y Palepu (2002, 1996); Claessens et al.(2000); Lefort y Walker (2002); Lefort y Walker (2000); Islas (2012); Salvaj y Couyoumdjian (2016); Salvaj (2012); Nazer et al.(2017), y Nazer (1993).
}

unidades argentinas en la primera mitad del siglo xx. Martínez (2015) se aproxima a la rentabilidad financiera de los mayores grupos chilenos en $2012^{5}$. Por otro lado, para el escenario latinoamericano se plantea que la rentabilidad de las grandes empresas se vincula con la presencia de mercados concentrados, los cuales favorecen la formación de precios. Además, se alude al papel de la disminución de los salarios reales en el aumento de la rentabilidad 6 . Por otro lado, se formula que a través de la diversificación no relacionada los grupos promueven la búsqueda de una rentabilidad general o agregada que compense las dificultades en determinadas empresas y/o sectores ${ }^{7}$.

El presente trabajo se propone contribuir al conocimiento de la rentabilidad de los grupos empresariales, aspecto escasamente tratado en la investigación histórico-económica. Esta aportación permite aproximarnos al desempeño de los grupos dentro de la economía chilena entre 1938 y $1988^{\circ}$. Así, a partir de fuentes primarias y secundarias se elaboran cinco cortes temporales para los años 1938, 1958, 1970, 1978 y 1988. Los tres primeros se insertan en diferentes etapas de la industrialización sustitutiva de importaciones chilena (1938-1973) -de aquí en adelante ISI-, mientras que los dos restantes se sitúan en el esquema neoliberal durante el régimen militar (1974-1988) ${ }^{9}$. El corte temporal de 1938 es construido para conocer el ROE en el año previo al lanzamiento oficial de la industrialización sustitutiva de importaciones en Chile, en un escenario de medidas proteccionistas con posterioridad a la crisis de 1929. En 1958 nos hallamos en el inicio de la fase difícil de la ISI, caracterizada por la saturación de los mercados que sustituyen importaciones en los bienes de consumo finales e intermedios, junto con la necesidad de incrementar los niveles de inversión en el segmento de bienes de capital $^{10}$. 1970 es el año que antecede al despliegue de las políticas aplic por el Gobierno socialista de la Unidad Popular entre 1971 y 1973. 1978 hace referencia a la fase de auge económico impulsada por el crédito externo durante el esquema monetarista implantado por el régimen militar entre 1974 y 1982. 1988 representa el auge exportador de la segunda mitad de la década de 1980 , en las postrimerías del régimen autoritario, en un escenario de mayor moderación y pragmatismo con respecto a la aplicación del modelo de libre mercado.

\footnotetext{
${ }^{5}$ Maito $(2016,2012)$ se aboca al cálculo de la tasa de ganancia de diversas economías. En referencia a la rentabilidad de la economía estadounidense examinada desde el enfoque marxiano de la tasa de ganancia, véase Shaikh (2016). Acerca del estudio de la rentabilidad en otros casos nacionales, véase Carrera (2007); Tafunell (2000); Mariña y Moseley (2000), y Rodríguez (1989)

${ }^{6}$ A su vez, autores como FitzGerald (1998) vinculan a la amplia protección comercial en la que se desenvuelven las empresas industriales durante la ISI con la obtención de rentabilidades suficientemente altas. Véase además, Santarcángelo (2012); Basualdo (2006), y Cademártori (1970).

${ }^{7}$ Véase Colpan y Hikino (2016).

${ }^{8}$ A este respecto, coincidimos con lo planteado por Cassis et al.(2016, pp. 3-6) en su trabajo sobre las grandes empresas europeas a lo largo del siglo xx: "Después de todo, el propósito de la historia empresarial es explicar el éxito o el fracaso de una compañía, una industria, y a un nivel más global, explicar la relación entre el desempeño empresarial y el desempeño económico [...] la rentabilidad financiera es la forma más habitual de evaluar el desempeño empresarial».

${ }^{9}$ Acerca de las referencias empleadas para la elaboración de los cortes temporales, véase gráfico 1.

${ }^{10}$ En torno a la ISI y el neoliberalismo en Chile, véase Sunkel (2011) y
} Ffrench-Davis (2008). 
Cada benchmark incluye a los ocho mayores grupos chilenos ordenados según el volumen del capital y reservas controlado. Esta decisión se refuerza aún más si consideramos que, en términos nominales, un grupo económico supone la presencia de un controlador de al menos dos empresas. La variabilidad que ello implica conduce a una excesiva dispersión con respecto a la unidad de estudio ${ }^{11}$. La constante de ocho grupos económicos por corte temporal únicamente se ve alterada en la medición de 1938, en donde se determinaron siete grupos de empresas ${ }^{12}$. La caracterización de la rentabilidad a través del ROE se refuerza si tenemos en cuenta que a lo largo del periodo considerado (1938-1988) el mercado de capitales desempeña un reducido papel en el financiamiento empresarial, debiendo las empresas autofinanciarse en una considerable medida y/o recurrir a créditos de corto plazo orientados al capital de explotación ${ }^{13}$. Por otra parte, dado que el capital y reservas es un indicador utilizado de manera profusa para describir la envergadura de las sociedades, otra de las ventajas de su uso radica en la posibilidad de realizar comparaciones de largo plazo ${ }^{14}$.

Este artículo se organiza del siguiente modo: luego de esta introducción, en la segunda sección se analizan las características de la rentabilidad financiera calculada de manera agre-

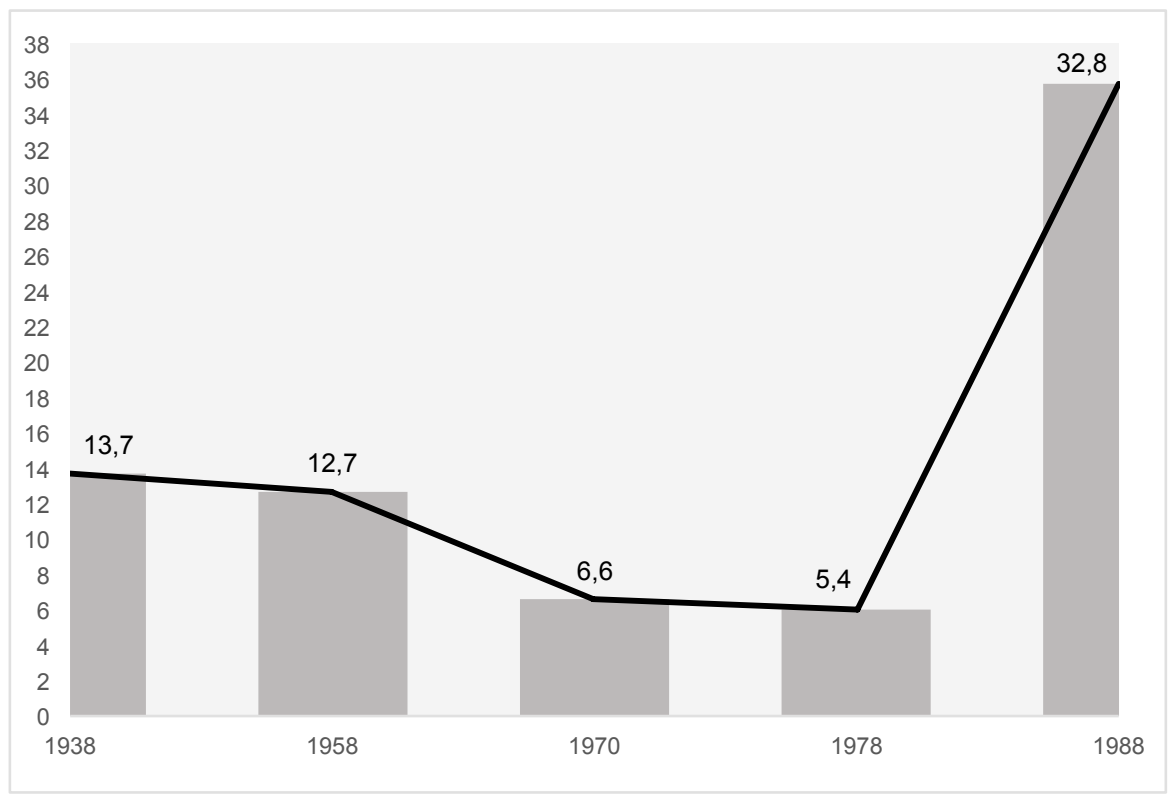

gada o conjunta, considerando a los mayores grupos empresariales chilenos entre 1938 y 1988. Este resultado se examina en relación con una variedad de dimensiones económicas e institucionales tales como: tamaño, concentración, carga impositiva a las utilidades, inflación y alza de costes energéticos. En el tercer apartado, se indaga en el papel de la demanda doméstica e internacional en la trayectoria de la rentabilidad de los grupos económicos en el largo plazo. En la última sección, se plantean las conclusiones de este trabajo.

\section{La rentabilidad financiera de los grupos económicos chilenos (1938-1988)}

En el gráfico 1 se presenta la rentabilidad promedio obtenida por el conjunto de grupos económicos para cada corte temporal. En 1938, la rentabilidad asciende a 13,7\%. Este resultado es representativo del $89,3 \%$ del capital y reservas total de los grupos en aquel año ${ }^{15}$. En 1958, en los inicios de la etapa difícil de la sustitución de importaciones, se registra un moderado descenso en la rentabilidad conjunta, la cual se sitúa en un $12,7 \%$. Este resultado cubre un $81,2 \%$ del capital y reservas globales. En 1970, se verifica una pronunciada caída en la rentabilidad, llegando esta al 6,6\%, con un descenso de algo más de un $49 \%$. Este valor representa un $77,2 \%$ de los recursos propios conjuntos. Más adelante, en la etapa monetarista neoliberal, el ROE obtenido en 1970 se reducirá aún más, llegando en 1978 a un $5,4 \%$, con una cobertura del $65,8 \%$ del capital y reservas totales. En 1988 se obtiene un elevado $32,8 \%$ de rentabilidad, que comprende al $86,6 \%$ del capital y reservas controlado por los grupos empresariales. De este modo, se registra un agudo incremento de la rentabilidad financiera, alcanzando el porcentaje más alto de la serie ${ }^{16}$.

Gráfico 1. Rentabilidad financiera (ROE) agregada grupos económicos según corte temporal (19381988).

Fuente: fuentes y publicaciones oficiales; Vial (2009); Carmona (2002); Martinic (2001); Monckeberg (2000); Beyer (1988); Dahse (1979); Garretón y Cisternas (1970); Sanfuentes (1964); Lagos (1960); Ramírez (1939), y Figueroa (1925).

\footnotetext{
${ }^{11}$ Este es el caso de contribuciones como la elaborada por Garretón y Cisternas (1970), en donde se identifican, en aquel año, a veintiún grupos económicos. En el listado de grupos se incluyen a inversores que no disponen de control empresarial, como Marín o Vial Espantoso, y a grupos de menor relevancia, como Lepe y/o Yarur Asfura

${ }^{12}$ No fue posible recabar la rentabilidad financiera del grupo Küpfer. Acerca de los grupos que componen cada corte temporal, véase el apéndice I.

${ }^{13}$ Este es un elemento compartido por las economías del subcontinente latinoamericano. Véase Bértola y Ocampo (2013) y Díaz-Alejandro (1985). Para el caso chileno, Bolsa de Comercio de Santiago (1988) e INSORA (1962). En este informe se señala que entre 1949-1960 las fuentes de capital se remitieron en un $52 \%$ a utilidades no distribuidas, y en un $48 \%$ a fuentes externas. De estas últimas, un $41 \%$ consistió en préstamos de corto plazo, un $4 \%$ a emisión de acciones, y un $3 \%$ en créditos de largo plazo.

${ }^{14}$ Considerando las contribuciones sobre grupos económicos editadas en Chile durante la ISI (Lagos, 1960; Garretón y Cisternas, 1970) y en la fase neoliberal (Dahse, 1979). Las unidades consideradas en el cálculo de la
}

rentabilidad financiera se presentan en el apéndice I. Para el cálculo del ROE se considera a las tres mayores empresas de cada grupo en base a los registros de la Bolsa de Comercio de Santiago. Esto nos permite captar la rentabilidad de las unidades de mayor tamaño, evitando las distorsiones generadas por la inclusión de empresas de menor envergadura en el cálculo de la rentabilidad. De manera excepcional, en grupos de menor tamaño se incluyen dos unidades.

${ }^{15}$ Véase apéndice I.

${ }^{16}$ Este porcentaje de la rentabilidad promedio de los grupos en 1988 es consistente con la tendencia de la segunda mitad de la década de 1980. A partir de datos recopilados para 1982, que cubren a las treinta mayores empresas industriales y financieras del país, el ROE es de $-5,4 \%$. Según los balances de 117 sociedades anónimas, se obtiene en 1985 una rentabilidad financiera (ROE) de -0,5\%. En 1986, la rentabilidad asciende abruptamente para situarse en un $15,5 \%$. En diciembre de 1987 el promedio de la rentabilidad financiera es de $20,1 \%$. El alza registrada coincide con la recuperación de la economía con posterioridad a crisis de la deuda externa. Véase Muñoz (1995). 
La evolución de la rentabilidad financiera de los principales grupos económicos chilenos entre 1938 y 1988 nos lleva a examinar diversos elementos para la explicación de esta trayectoria. En primer lugar, el incremento del tamaño de los grupos no supone la obtención de altas rentabilidades. En la fase de máxima expansión de los conglomerados, lo cual nos remite al cote temporal de 1978 , los grupos cubren un $17,1 \%$ del PIB,y controlan el 76,9\% de las empresas cotizantes en el mercado bursátil ${ }^{17}$. La rentabilidad conjunta de los grupos es de $5,4 \%$, cifra inferior a la rentabilidad global captada en la culminación de la fase difícil de la ISI, en 1970 (ROE 6,6\%), año en que los grupos cubren un $5,3 \%$ del producto ${ }^{18}$. Así, la rentabilidad no evoluciona en consonancia con el tamaño de los grupos empresariales, definido por el incremento en el monto del capital y reservas controlado.

La economía chilena se caracteriza, en el largo plazo, por constituirse como una estructura económica concentrada ${ }^{19}$. No obstante, la concentración económica no presupone el logro de elevadas rentabilidades por intermedio de la gestión de precios o volúmenes de producción como consecuencia del poder de mercado por parte de los grupos. Así, por ejemplo, para las mediciones de 1958 y 1970 la neutralización de las posibilidades brindadas por la estructura concentrada de los mercados se vincula con los reajustes salariales por encima del costo de la vida, práctica usual durante la ISI que conduce a una tendencia ascendente en los salarios reales ${ }^{20}$. Este fenómeno contribuye a mitigar los efectos de una estrategia formadora de precios en segmentos concentrados. Con respecto al corte temporal de 1978, la caída de la demanda interna, caracterizada por el descenso de los salarios reales y el incremento del desempleo con motivo de la recesión del mercado interno, se relaciona con las profundas medidas antiinflacionarias de corte monetarista implementadas por el Gobierno militar, considerando la contracción de la emisión monetaria y el gasto público, la desregulación del sector financiero, el alza desmedida de las tasas de interés y el endeudamiento externo, junto a la competencia de productos importados con oportunidad de una indiscriminada apertura comercial ${ }^{21}$. Este escenario

\footnotetext{
${ }^{17}$ Véase Dahse (1979) y Bolsa de Comercio de Santiago (1978).

${ }^{18}$ Acerca de la proporción de los grupos en relación al PIB, véase XXX.

19 Es reconocido el carácter altamente concentrado de la economía chilena, en donde diversos mercados se articulan como monopolios u oligopolios. Esta característica es examinada por Kirsch (1977) en el periodo que antecede a la Gran Depresión, y se profundiza en el transcurso de la ISI, como demuestra el trabajo de Gasic (1971), persistiendo esta característica en el esquema de libre mercado. Así, por ejemplo, mercados como el carbón (con posición predominante de Cousiño, Claude); papel y celulosa (con posición dominante del grupo Matte); bebidas, azúcar (con posiciones relevantes de los grupos Edwards, Cruzat-Larraín y Luksic en diversos periodos); textil (con posiciones prevalecientes de Yarur, Said); pesquero (con posición relevante de Angelini), son segmentos altamente concentrados. Recién en 1959, se establece la primera norma antimonopolios del país, la Ley 13305 . Esta se aboca a la persecución de prácticas monopólicas como la colusión o la fijación concertada de precios sin adentrarse en la estructuración de la propiedad y/o el control empresarial.

${ }^{20}$ Véase el gráfico 7. Acerca de los reajustes de sueldos y salarios durante la ISI, Reyes (2015); Pinto (1973), y Ramos (1972).

${ }^{21}$ En promedio, la tasa de interés real entre 1975 y 1980 es de 34,7\%. Véase Banco Central de Chile (2001). Acerca del neoliberalismo en el Gobierno autoritario, véase Sunkel (2011); Ffrench-Davis (2008); FfrenchDavis y Stallings (2001). Sobre los niveles del desempleo en el modelo de
} libre mercado, véase el cuadro 3. repercutirá en la realización o venta de la producción doméstica en los mercados. Esta condición del mercado interno en el monetarismo contribuye a morigerar los efectos potenciales de la concentración económica con respecto a las utilidades obtenidas y la rentabilidad captada, incluso en un escenario impositivo altamente favorable ${ }^{22}$. Por tanto, es posible aseverar, para el periodo en estudio, que la estructura económica concentrada de la economía chilena no asegura la obtención de altas rentabilidades.

En este orden de cosas, cabe plantearse si la trayectoria del impuesto a la renta empresarial se constituye como un elemento que incide en la evolución de la rentabilidad. En términos teóricos, es de esperar que las variaciones del nivel impositivo influyan en la rentabilidad financiera. Hacia 1970, nos encontramos ante un periodo de elevados gravámenes a la renta empresarial ${ }^{23}$. Es razonable esperar que, con el propósito de contrarrestar las consecuencias del impuesto, un agudo incremento de la carga tributaria a las utilidades estimule la formación de precios al alza en una estructura económica concentrada como la chilena.

Como es sabido, existieron controles de precios aplicados a lo largo del modelo industrializador ${ }^{24}$. En lo fundamental, estos se relacionan con bienes de primera necesidad. Dichos controles de precios se mostraron incapaces de contener la tendencia inflacionaria. En el aumento de precios registrado entre 1953-1955, se alcanzará las características de inflación galopante, con un máximo de 83,8 \% en $1955^{25}$. Desde entonces, a pesar de la obtención de breves y esporádicos descensos, el nivel de precios se ubicará, en promedio, alrededor del $20 \%$ anual. El impacto de la inflación en la capacidad de compra tenderá a ser mitigado por la aplicación de corrección monetaria a los salarios nominales, recuperando el poder adquisitivo de la población y neutralizando los efectos del alza de precios como un potencial paliativo del incremento impositivo ${ }^{26}$.

Como se ha señalado, en los inicios del modelo monetarista-neoliberal, entre 1974-1975, el impuesto a las utilidades se reducirá a 15 puntos porcentuales; para, desde 1976, posicionarse en un $10 \%$ y mantenerse como tal a lo largo del régimen militar, es decir, incluyendo los cortes temporales de 1978 y $1988^{27}$. Este impuesto a la renta empresarial es, por ese entonces, el de menor envergadura entre las economías industriales y semi-industrializadas como la chilena. Por tanto, si la rentabilidad financiera dependiese de la variabilidad de la carga impositiva a las empresas, debe verificarse un aumento sustantivo de la misma una vez que se reduce, de manera aguda,

\footnotetext{
${ }^{22}$ Impuesto a la renta empresarial que experimenta un abrupto descenso desde un $35 \%$ en 1973 a un $15 \%$ en 1974.

${ }^{23}$ En 1964, el impuesto a la renta empresarial se fija en un 30\%, con un alza de 13 puntos porcentuales con respecto a su valor anterior. Entre 1946 y 1963 este impuesto varía entre un $11 \%$ y un $17 \%$. Véase, Jeftanovic (1979); Gobierno de Chile (1974), y Servicio de Impuestos Internos de Chile. Dirección General de Impuestos Internos (1960).

${ }^{24}$ Acerca de los controles de precios durante la industrialización sustitutiva de importaciones, Haindl (2008) y Ffrench-Davis (2008).

${ }^{25}$ Véase gráfico 8.

${ }^{26}$ Véase Landerretche (1983). Similar orientación en torno a considerar a la estructura concentrada de los mercados y la pugna distributiva para comprender el proceso inflacionario durante la ISI se halla en Sunkel (2011) y Mamalakis (1976).

${ }^{27}$ Este Gobierno concluye en marzo de 1990.
} 


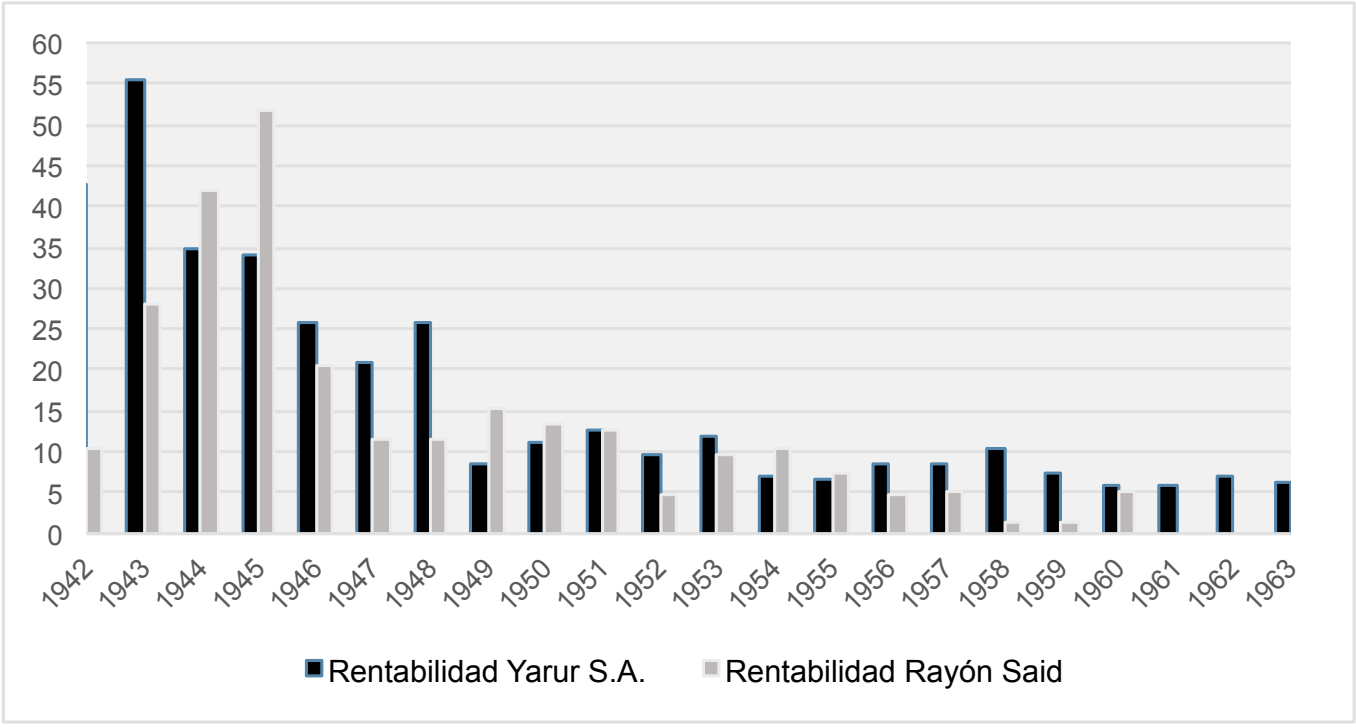

Gráfico 2. Elevadas rentabilidades financieras en la etapa fácil de sustitución de importaciones y su descenso en la fase difícil. Empresas Yarur y Rayón Said (1942-1963).

Fuente: elaboración propia a partir de Sanfuentes (1964). la presión tributaria. Sin embargo, esto no acontecerá en el recesivo escenario monetarista chileno; más bien ocurrirá, lo contrario: la rentabilidad de los grupos económicos se situará en un nivel inferior al captado a fines de la ISI en 1970, llegando a un 5,4\%. En suma, la evolución del impuesto a las utilidades no determina los valores de la rentabilidad de los grupos, por lo que el movimiento de este indicador permanece sujeto a otras fuerzas que, como examinaremos más adelante, se vinculan con la evolución de la demanda interna y externa.

Ahora bien, es probable que durante la fase difícil de la ISI, la subida de los precios al consumidor, relacionada con el brote inflacionario del primer lustro de la década de 1950, genere un escenario de expectativas negativas con respecto al consumo, viéndose afectada la demanda interna.

El gráfico 2 presenta la evolución de los valores ROE de las dos mayores empresas controladas por los principales grupos económicos textiles, Yarur y Said, entre 1942 y 1963. Debido a la extensión de los datos, se describe la evolución de la gran unidad del grupo Yarur. La rentabilidad financiera exhibe un elevado nivel en la etapa fácil de la ISI, caracterizada por la cobertura de la demanda preexistente y conocida en los mercados nacionales de bienes de consumo no durable. Desde fines de la década de 1940, surge una tendencia descendente que se agudiza a lo largo de la ISI. En 1958, la rentabilidad de la empresa Yarur $(10,5 \%)$ se aproxima al promedio obtenido por los grupos económicos en aquel año (12,7\%). Entre 1951 y 1960, en la fase difícil de sustitución de importaciones, las ganancias de la mayor empresa textil sudamericana descenderán de forma aguda hasta situarse en un promedio de $8,9 \%$, valor asimilable al registrado en el corte temporal de 1970 para el conjunto de los grupos económicos (6,6\%). El abrupto descenso de la rentabilidad, registrado entre 1948 y 1949, precede al alza inflacionaria acontecida en la primera mitad de la década de 1950, en donde la inflación se elevará desde un $12 \%$ en 1952 a un $56,1 \%$ en $1953^{28}$. Asimismo, la disminución de la rentabilidad en el segmento textil se manifiesta con anterioridad al alza del impuesto a las utilidades en 1964.

28 Véase gráfico 8.
Por tanto, aun estimando que, a pesar de los reajustes de sueldos y salarios, la inflación desempeñase un papel negativo en las expectativas de consumo, esta no es determinante con respecto a los hitos en la evolución de la rentabilidad de un sector clave en la industrialización como el textil, el cual, en la década de 1950, representa alrededor del 17\% del valor agregado industrial chileno ${ }^{29}$. Lo hasta aquí expuesto nos sugiere que las magnitudes de la rentabilidad de los grupos económicos, tendencialmente altas en la primera etapa de sustitución fácil de la ISI, no se relacionan con el nivel de precios al consumidor. La subida de precios de la década de 1950 es contemporánea con la tendencia a la saturación del envite de sustitución de importaciones en los mercados, en donde se completa la cobertura de la demanda doméstica en el sector de bienes de consumo no durable e intermedio ${ }^{30}$. Con excepción del incremento inflacionario de 1953-1955, la inflación a lo largo de la ISI y durante el Gobierno militar se manifiesta como un hecho reconocible, por lo que probablemente estaría incorporada al acervo de la toma de decisiones por parte de los agentes económicos.

Esta alza inflacionaria se ha adjudicado a los efectos del sector externo una vez que repercute en el descenso de las exportaciones cupríferas la finalización de la guerra de Corea (1950-1953), junto a la presencia del déficit público que conduce a una mayor emisión ${ }^{31}$. Expresado lo anterior, y de un modo preliminar, es pertinente considerar la vinculación entre el descenso de la rentabilidad financiera y la culminación de la cobertura de los mercados en la primera fase de la ISI de manera conjunta con el alza inflacionaria entre 1953$1955^{32}$

\footnotetext{
${ }^{29}$ Véase CEPAL (1962).

30 Véase cuadros 2 y 3.

${ }^{31}$ Haindl (2008) y Meller (2007).

${ }^{32} \mathrm{Si}$ bien no es el propósito de este artículo dilucidar los factores que inciden en esta problemática crucial de la economía chilena en el transcurso de la ISI, cabe considerar este probable condicionante con respecto a dicho repunte inflacionario.
} 


\begin{tabular}{lrr} 
Bienes (rama) & $\mathbf{1 9 2 5 - 1 9 2 9}$ & $\mathbf{1 9 5 1 - 1 9 5 5}$ \\
Tejidos de algodón & & \\
Importaciones & 93,46 & 1,52 \\
Producción país & 6,54 & 98,48 \\
\hline Paños de lana & & \\
Importaciones & 67,71 & 5,08 \\
Producción país & 22,29 & 94,92 \\
\hline Hierro y acero & & \\
Importaciones & & 18,33 \\
Producción país & 84,67 & 81,77 \\
& 15,33 & \\
\hline Metalurgia & & 41,27 \\
Importaciones & & 59,63 \\
Producción país & 76,46 & \\
\hline
\end{tabular}

Cuadro 1. Producción nacional de determinados bienes que sustituyen importaciones (1925-1955). Porcentajes promedios anuales.

Fuente: cálculo de porcentajes y elaboración propia a partir de SOFOFA (1963).

En el cuadro 1 se observa el alcance del proceso de sustitución de importaciones en cuatro rubros relevantes. En comparación con el periodo previo a la Gran Depresión, hacia mediados de 1950, en el segmento de géneros de algodón donde se desempeña el grupo Yarur, y en paños de lana, se produce casi el $100 \%$ de lo consumido en el país.

\begin{tabular}{|lcc|}
\hline Ramas industriales & $\mathbf{1 9 2 7}$ & $\mathbf{1 9 6 3 - 1 9 6 4}$ \\
\hline Alimentos, bebidas, tabaco & 11,4 & 12,2 \\
\hline Productos de la madera & 4,9 & 2 \\
\hline Papel e imprentas & 42 & 13 \\
\hline Productos químicos & 71,3 & 38 \\
\hline Prod. minería no metálica & 75,5 & 11,1 \\
\hline
\end{tabular}

Cuadro 2. Porcentaje de importaciones a nivel sectorial (1927/1963-1964). Fuente: elaboración propia a partir de Muñoz (1968).

Se aprecia en el cuadro 2 que las ramas de alimentos y bebidas -en donde se ubica con una presencia significativa del grupo Edwards, con empresas monopólicas como la Compañía Cervecerías Unidas (CCU) y la azucarera Compañía Refinería de Azúcar de Viña del Mar (CRAV) - se encuentran, prácticamente, sustituidas desde una fecha anterior a la implementación de la ISI. El papel es otro bien que a mediados de 1960 se halla sustituido. Esta actividad es liderada por el grupo Matte, propietario de la Compañía Manufacturera de Papeles y Cartones (CMPC), empresa monopólica en este rubro. Asimismo, es evidente el esfuerzo de sustitución de importaciones en el segmento de minerales no metálicos y los productos químicos, aunque persiste un importante nivel de compras en el exterior.

\begin{tabular}{cc}
\hline 1970 & 5,9 \\
\hline 1971 & 5,2 \\
\hline 1972 & 4,1 \\
\hline 1973 & 4,8 \\
\hline 1974 & 9,1 \\
\hline 1975 & 15,7 \\
\hline 1976 & 16,7 \\
\hline 1977 & 13,3 \\
\hline 1978 & 13,8 \\
\hline 1979 & 13,5 \\
\hline
\end{tabular}

\begin{tabular}{cc}
\hline 1980 & 11,7 \\
\hline 1981 & 10,4 \\
\hline 1982 & 19,6 \\
\hline 1983 & 18,7 \\
\hline 1984 & 16,3 \\
\hline 1985 & 13,8 \\
\hline 1986 & 10,6 \\
\hline 1987 & 10,6 \\
\hline 1988 & 8,9 \\
\hline
\end{tabular}

Cuadro 3. Tasas de desempleo abierto de la economía chilena, porcentajes para cada año (1970-1988).

Fuente: elaboración propia a partir de Banco Central de Chile (2001); Jadresic (1986).

Como una muestra de la situación de la demanda interna en el neoliberalismo, se describe en el cuadro 3 el aumento del desempleo de la fuerza de trabajo. A partir de 1974 se transita desde de una economía que a fines de la ISI experimenta el pleno empleo a unos niveles de desocupación que casi de forma permanente se ubican por encima de los dos dígitos. Entre 1976 y 1985 las cifras de desempleo se incrementarían entre 5 y 6 puntos porcentuales si se considera en la estimación los planes de emergencia ocupacional proveídos por el Gobierno. Así, en 1983, en plena crisis de la deuda externa, la sumatoria del desempleo abierto y encubierto superará el 30\% de la fuerza de trabajo.

Por último, no es posible plantear la incidencia de un shock energético que interfiera en la rentabilidad de los grupos económicos chilenos. Como es sabido, hasta 1973 la tendencia de los precios del petróleo se orienta a la estabilidad. El alza de precios repercute en la economía chilena entre 1973 y la recesión de 1975, periodo no contemplado en los cortes temporales y caracterizado por la convulsión generada en el país con motivo de la crisis político-institucional de 1973 y el importante descenso en el nivel de actividad en 1975 (-12,9\%) a raíz del impacto de la recesión internacional y las medidas de ajuste interno. Por otro lado, el precio del carbón presenta la misma evolución tendiente a la estabilidad en el largo plazo con una subida a partir de 1973. Entre 1976 y 1981, con una tasa del PIB y promedio de 7,3\%, el alza de precios del petróleo ya se encuentra asimilada por la economía, cuestión captada en el corte temporal de $1978^{33}$. A su vez, desde 1985 los precios internacionales del crudo se encuentran en una fase descendente que se mantiene en el corte temporal de 1988, prolongándose esta tendencia hasta $1998^{34}$.

\footnotetext{
${ }^{33}$ Acerca de las variaciones anuales del PIB, véase Banco Central de Chile (2001).

${ }^{34}$ En torno a la evolución del sectorial del carbón en el marco de la ISI y el neoliberalismo, véase Yáñez y Garrido (2015, 2017). La serie histórica de precios internacionales del petróleo se encuentra en: http://www.macrotrends.net/1369/crude-oil-price-history-chart (revisado el 15 de abril de 2018). La serie histórica de precios internacionales del carbón se encuentra disponible en: Federal Reserve Saint Louis (2018).
} 


\section{El movimiento de la demanda y la rentabilidad de los grupos empresariales chilenos (1938-1988)}

En lo que sigue, se examina el papel desempeñado por la demanda interna y externa en la evolución de la rentabilidad

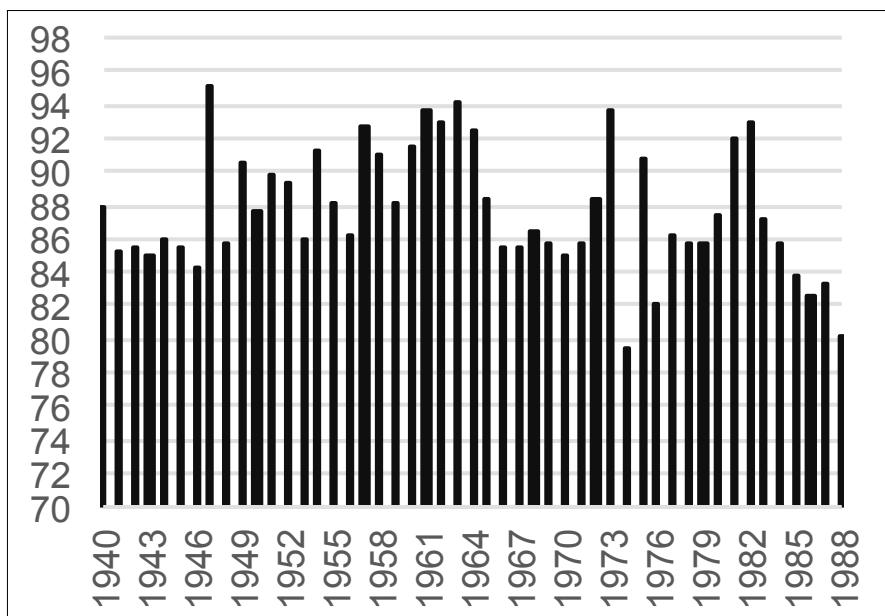

Gráfico 3. Demanda efectiva (consumo + inversión) como \% PIB, 1940-1988. Fuente: elaboración propia a partir de Díaz et al. (2010).

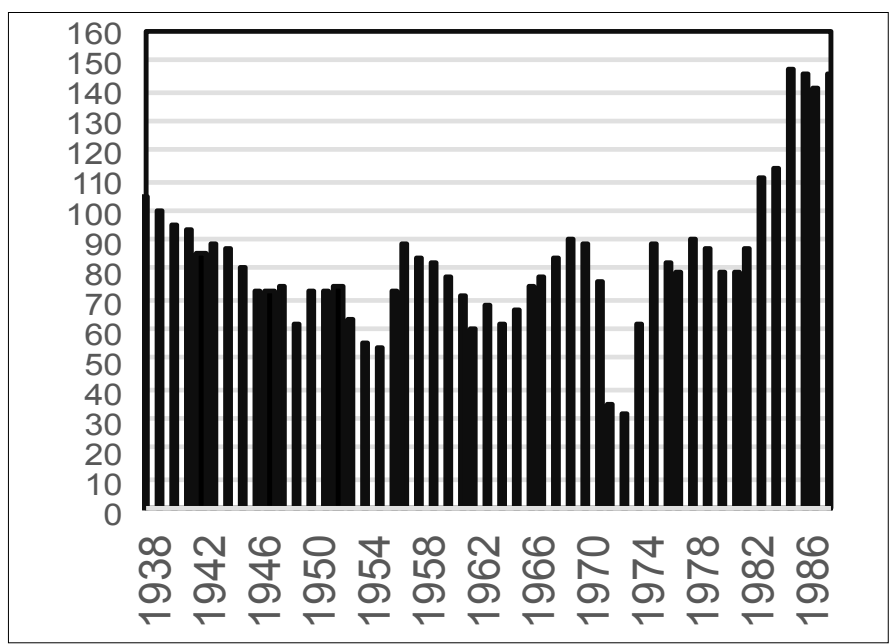

Gráfico 5. Tipo de cambio real 1938-1988 (1996 = 100).

Fuente: elaboración propia a partir de Díaz et al. (2016).

Con respecto a la evolución de la rentabilidad de los grupos empresariales, en 1940 la demanda efectiva supone un $87,7 \%$ del PIB con una tendencia, a lo largo de la década, a estabilizarse en torno a un $85 \% 35$. Si bien no se dispone de información

\footnotetext{
35 Se considera a la demanda efectiva como el componente crucial de la demanda interna. Así, en lo sucesivo, cuando se utilizan los términos "demanda interna» o "demanda doméstica» se hace referencia a consumo privado e inversión. Se excluye del análisis al gasto estatal, abocado en lo fundamental a infraestructura, vivienda y gasto social, ítems que no participan de los mercados en que se desenvuelven los grupos económicos del país. En el corte temporal de 1988, la presencia de grupos resultantes de las privatizaciones en el sector eléctrico y energético, y con anterioridad, en materiales de construcción en el caso del grupo Matte durante la ISI, no implica una vinculación de la acción estatal con los ejes de la acumulación de capital de estos grupos. En 1988, el Estado no activa ninguna gran obra de inversión ligada a los grupos privatizados entre 1987 y 1988. Por otro lado,
}

financiera de los grupos empresariales. En el gráfico 3 se aprecia la demanda efectiva entre 1940 y 1988 como porcentaje del PIB. En una economía semicerrada durante la ISI y abierta al comercio exterior en el libre mercado, el papel de la demanda internacional es captado a través de las exportaciones netas (gráfico 4).

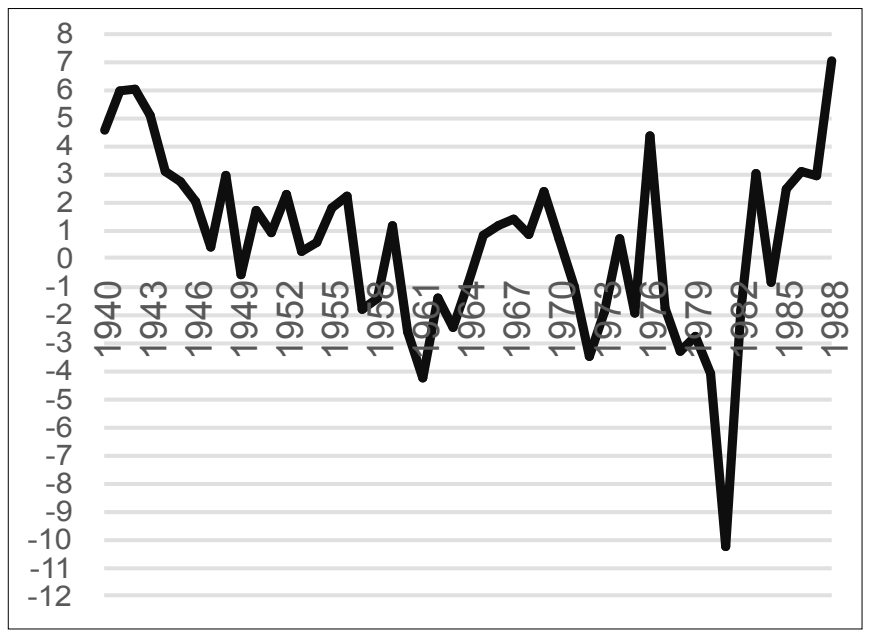

Gráfico 4. Exportaciones netas como \% PIB, 1940-1988.

Fuente: elaboración propia a partir de Díaz et al. (2010).

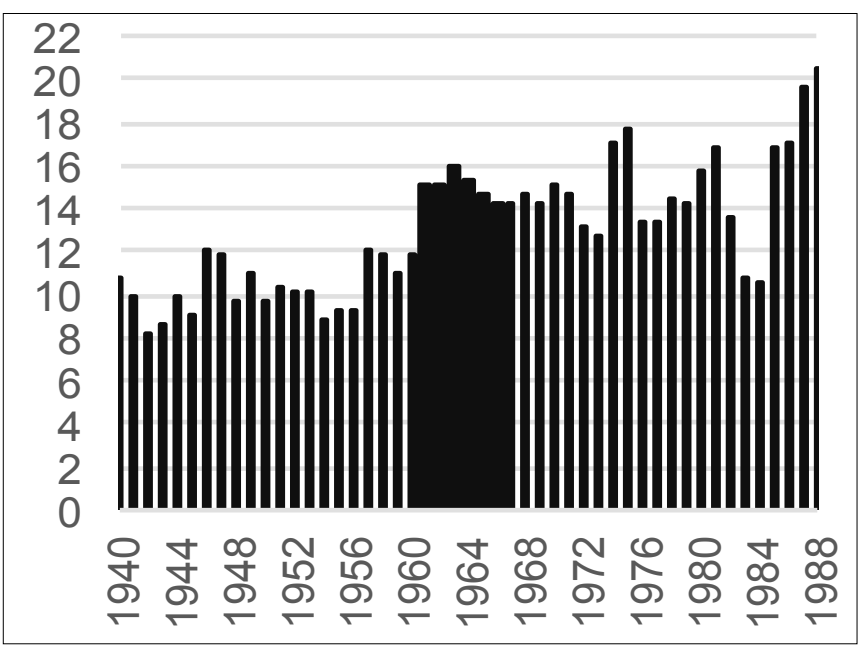

Gráfico 6. Inversión en capital fijo como \% PIB, 1940-1988.

Fuente: elaboración propia a partir de Díaz et al. (2010).

sobre la demanda interna para 1938, es posible efectuar una aproximación al año final de la recuperación económica con motivo del impacto de la Gran Depresión mediante los datos registrados en $1940^{36}$. Recordemos que en 1938 la rentabilidad promedio de los grupos es de un $13,7 \%$.

en el grupo Matte los materiales de construcción se ubican en una posición secundaria con respecto al núcleo de actividad del grupo la industria del papel y celulosa. Por último, los grupos carboníferos Cousiño y Claude experimentan a lo largo de la ISI el paulatino envite de la sustitución de este recurso por el petróleo, situación agravada durante la década de 1960. La incidencia de la demanda privada y estatal (ferrocarriles del Estado) es captada en el ROE de los cortes temporales de 1938, 1958, y 1970.

${ }^{36}$ A escala internacional, Chile es el país más afectado por las repercusiones de la crisis de 1929, con un descenso del PIB por encima de $26 \%$ en 1932. Véase Sunkel (2011) y Meller (2007). 


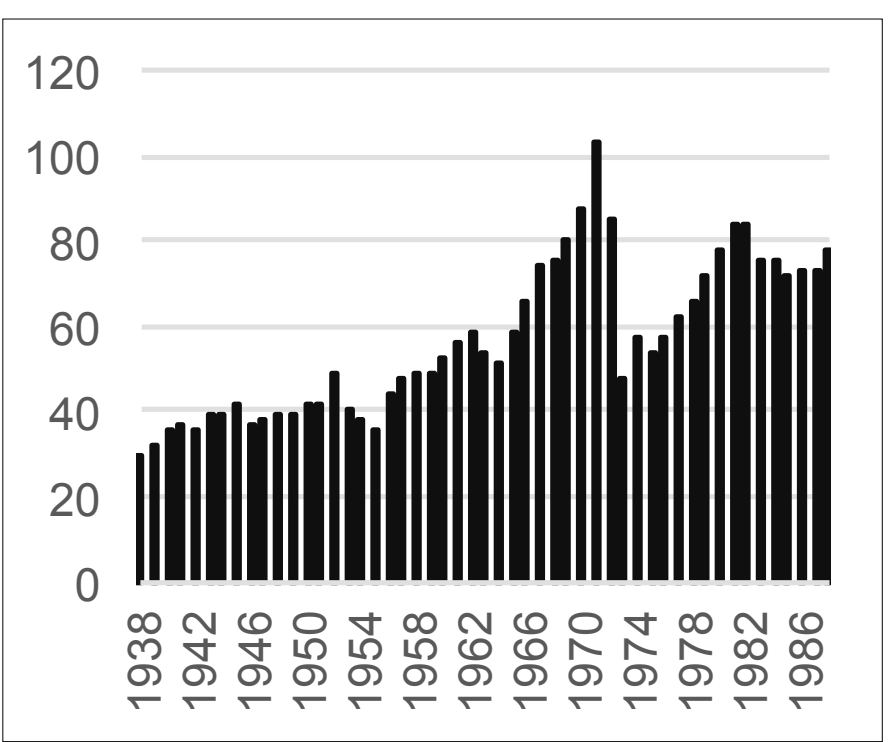

Gráfico 7. Salarios reales (1938-1988) ${ }^{37}$.

Fuente: elaboración propia a partir de Díaz et al. (1995).

En 1958, la demanda interna cubre un $91 \%$ del PIB. Como se ha indicado, en ese año la rentabilidad de los grupos económicos se sitúa en un 12,7\%. Desde 1963 se revierte la tendencia al alza en este indicador con una trayectoria descendente de la demanda en la fase de sustitución difícil de importaciones. En 1970, el valor de la demanda es de un $85,1 \%$ del producto y la rentabilidad de los grupos desciende a un 6,6\%. Por otro lado, entre 1971 y 1973 se aprecia un ascenso de la demanda doméstica coincidente con el incremento del consumo a raíz de la profundización de la dinámica redistributiva llevada a cabo por el Gobierno socialista de la Unidad Popular. Más adelante, en un mercado interno recesivo a partir de la implantación del neoliberalismo, se observa una caída de la demanda interna, que en 1978 recupera una envergadura similar a 1970, con un monto del 85,8\% del PIB. En 1978 las rentabilidades financieras de los grupos económicos persisten a la baja, y obtienen un $5,4 \%$. Durante la crisis financiera de 1982-1983, la crudeza de la misma se experimenta a partir de 1982 , cuando se produce un abrupto descenso de la demanda. En 1988 la demanda se sitúa en $80,1 \%$ del PIB.

La evolución de la demanda doméstica coincide con el movimiento de la rentabilidad financiera de los grupos empresariales, a excepción del año 1938 y, de manera especial, 1988, año en donde la demanda presenta la menor envergadura de la serie, manifestándose en cambio, y de manera notable, la rentabilidad más alta del periodo examinado, con un $32,8 \%$. En este escenario, es en donde adquiere un papel central la demanda externa. Así, en 1988, y en un contexto de apertura comercial y equilibrios macroeconómicos favorables al sector externo, es la demanda internacional, caracterizada por la expansión de las exportaciones netas globales, el elemento que explica el agudo aumento de la rentabilidad financiera, desde el 5,4\% registrado en 1978 hasta un 32,8\%. En 1988, las exportaciones netas son las más altas de la serie, y representan un 6,9\% del PIB.

Como es sabido, el cobre es el recurso central de las exportaciones chilenas. Entre 1938 y 1988, en promedio este sector re-

\footnotetext{
$371995=100$. Incluye salarios y sueldos.
}

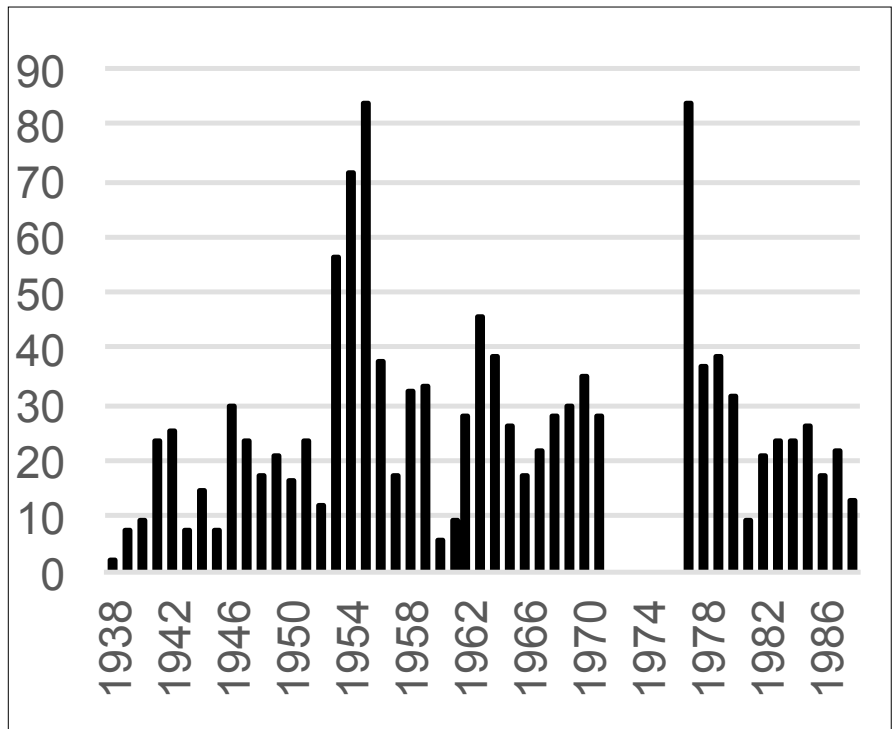

Gráfico 8. Inflación (IPC) (1938-1988) ${ }^{38}$.

Fuente: elaboración propia a partir de Díaz et al. (2016).

presenta un 75,6\% del total exportado por el país. No obstante, entre 1938 y 1985 el valor de las exportaciones del metal rojo, en términos reales y nominales, no coevoluciona con la rentabilidad de los grupos empresariales. Sí coincide la rentabilidad de los grupos en 1988 con la abrupta subida del valor de las exportaciones cupríferas entre 1986 y $1988^{39}$. Dicho evento es contemporáneo al alza de las exportaciones no tradicionales, segmento en donde operan grupos económicos posicionados como líderes sectoriales, como es el caso de Matte, controlador de la Compañía Manufacturera de Papeles y Cartones, en la exportación de celulosa y papel; Angelini, en la actividad pesquera y forestal mediante el control de Eperva, Indo, y Maderas Cholguán; y Lecaros, en el segmento pesquero con el control de Coloso y San José. Asimismo, cabe considerar a Luksic a través del control del monopolio Compañía Cervecerías Unidas. De igual forma, las exportaciones netas también presentan un valor elevado en la fase inicial de la ISI, aunque no de la envergadura del registrado en el neoliberalismo desde 1984 (véase gráfico 4). Lo anterior, se condice con la evolución del tipo de cambio real, que presenta unos valores ascendentes en el inicio de la industrialización sustitutiva de importaciones, al igual que con posterioridad a la crisis económica de 1982-1983 (véase gráfico 5).

Por tanto, es la combinación entre mercados internos en proceso de sustitución de importaciones con una demanda doméstica preexistente, conocida y por satisfacer, junto a los valores de las exportaciones netas en el contexto de la Segunda Guerra Mundial -demanda externa- los elementos que contribuyen a explicar la rentabilidad financiera de los grupos económicos en los primeros años de la industrialización sustitutiva de importaciones ${ }^{40}$. Similar situación con respecto al

\footnotetext{
${ }^{38}$ Para una mejor visualización del movimiento de los precios se omite el periodo de hiperinflación entre 1972 y 1976, en donde en promedio esta alcanza niveles de $354 \%$, con un máximo en 1973 , de $606 \%$. Véase Díaz et al. (2016).

${ }^{39}$ Acerca de los datos de las exportaciones cupríferas, véase Díaz et al. (2016).

${ }^{40}$ Así, por ejemplo, entre 1939 y 1945, en el transcurso de los Gobiernos radicales de Pedro Aguirre Cerda (1939-1941) y la primera mitad del
} 


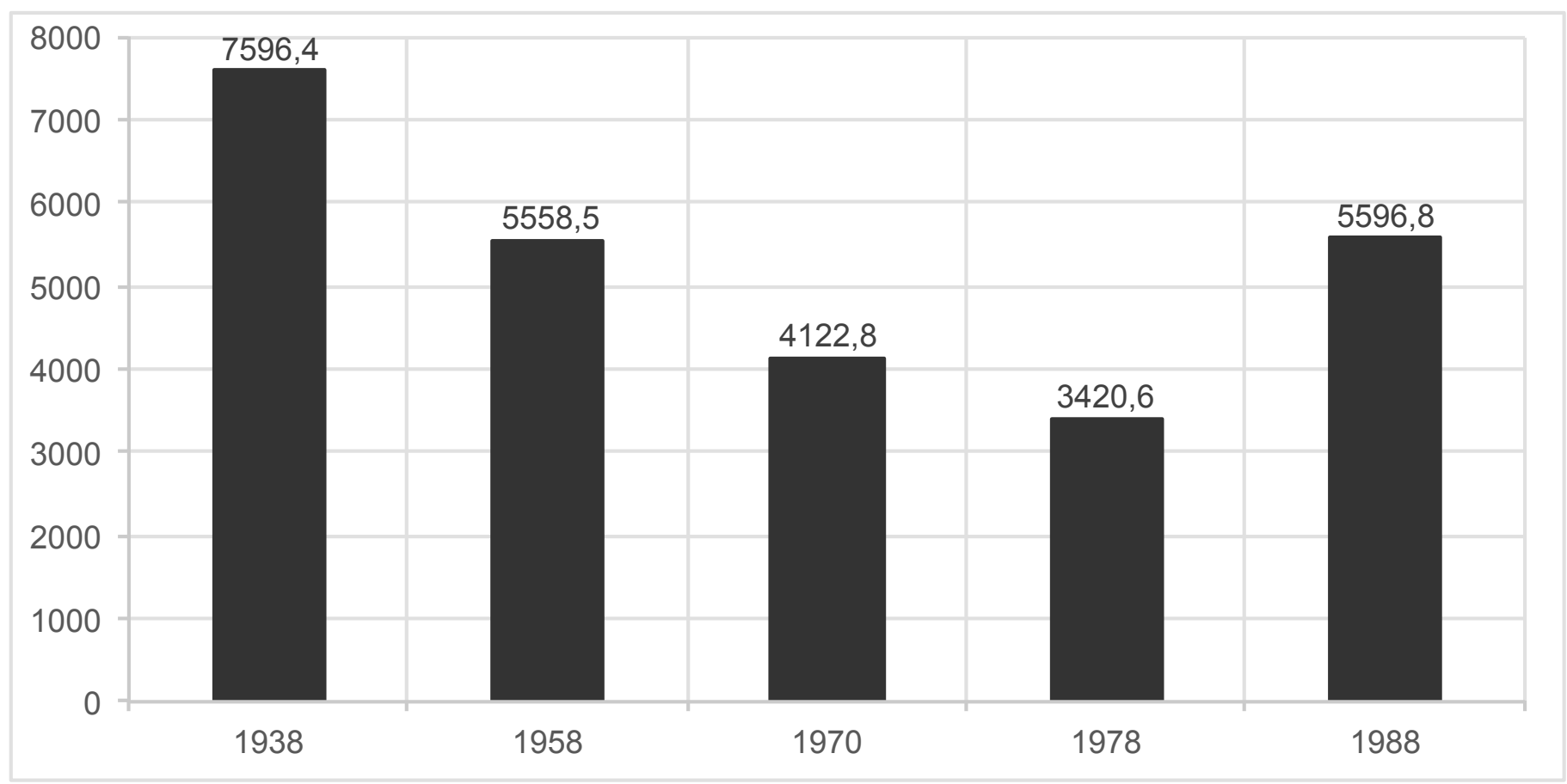

Gráfico 9. Índice de diversificación Herfindahl-Hirschman, grupos económicos (1938-1988).

Fuente: elaboración propia.

sector externo, acontecerá en el neoliberalismo, con posterioridad a la crisis económica de 1982, siendo el incremento de las exportaciones netas el impulso central en el vertiginoso ascenso de la rentabilidad de los grupos económicos en 1988. Por otra parte, tanto en 1938 como en 1988 la inflación se encuentra entre los valores más reducidos de la serie (véase gráfico 8). A este respecto, dado que no es derivable una causalidad entre las fluctuaciones de la inflación y el ROE captado, este rasgo nos sugiere que la estabilización del ambiente macroeconómico en ambos extremos del periodo acompaña al fuerte impulso de la demanda doméstica y externa sobre la rentabilidad.

Por otro lado, las dificultades de los ciclos productivos en que se desenvuelven grupos económicos con sectores de actividad predominante e integrados verticalmente, como Cosatán (salitre), Menéndez (agropecuario), Cousiño (carbonífero) y Claude (carbonífero) muestran el influjo de la trayectoria sectorial sobre la rentabilidad financiera. Las distintas problemáticas que afectaron a los sectores mencionados -competencia externa en el caso del salitre, crisis productiva y conflictividad institucional en el sector agropecuario, competencia del petróleo como bien sustituto y problemas de productividad en el carbón- dan cuenta de complejidades que los grupos económicos mencionados serán incapaces de revertir. El impacto del descenso de la demanda en la evolución del ciclo de negocios de ambos segmentos se verá reflejado en la caída de la renta-

periodo de Juan Antonio Ríos (1942-1946) se asiste a un elevado PIB industrial, con una tasa de crecimiento promedio de la manufactura entre $1939-1943$ de $13,81 \%$, el mayor registrado entre 1938 y 1988 . El segundo mayor registro quinquenal del producto industrial se manifiesta entre 1984 y 1988 con un 6,65\%. Cálculos propios a partir de Díaz et al. (2010). bilidad y, con ello, en su presencia entre los principales grupos económicos del país ${ }^{41}$.

Con la finalidad de conocer la relación entre la evolución del ROE y la diversificación no relacionada de los grupos empresariales, se calcula el porcentaje sectorial de cada grupo según el capital y reservas registrado en los segmentos productivos, comerciales o financieros, con base en el índice Herfindahl-Hir$\operatorname{schman}^{42}$. Este nos ilustra acerca del nivel de diversificación o el grado de concentración de las actividades realizadas por los grupos. Al existir una mayor concentración -o nula diversificación - el índice adquiere el valor máximo de 10000 puntos (100 x 100). Así, por ejemplo, con un valor por debajo de 18002000 puntos estaríamos en presencia de una diversificación sin negocio dominante.

Observamos en el gráfico 9 que en 1938 nos encontramos ante la menor diversificación sectorial. A lo largo de la industrialización sustitutiva de importaciones, la evolución del índice refleja un incremento de la diversificación cuyo punto máximo se logra en el neoliberalismo (1978), con la formación de los grandes conglomerados, año en que, por otro lado, se obtiene el mínimo valor del ROE. Más adelante, hacia 1988, con posterioridad a la crisis económica de 1982-1983, se asiste a una reducción de la diversificación. De este modo, el incremento de la diversificación captada por el índice no se condice con una mejora de la rentabilidad, la diversificación no favorece el alza del ROE o, dicho de otro modo, no interrumpe la tendencia

\footnotetext{
${ }^{41}$ Para la trayectoria del ROE de los grupos con actividad dominante, véase apéndice I.

${ }^{42}$ Se emplea un nivel de desagregación de dos dígitos extraído de la Clasificación Industrial Internacional Uniforme (CIIU), tercera revisión de 1989. De ser necesario, se considera la cuarta y última revisión de la CIIU (2002). El valor del Herfindahl para cada grupo según corte temporal se encuentra en el apéndice I.
} 
a la reducción de la rentabilidad en el periodo considerado, permaneciendo esta evolución supeditada al movimiento general de la demanda.

Por último, la evolución de la rentabilidad financiera de los grupos económicos chilenos permite aproximarnos a los niveles de la inversión en capital fijo (gráfico 6). Considerando que a lo largo de la ISI el Estado es responsable de un promedio cercano al 50\% de la inversión, y esta entre 1940 y 1970 es de un $11,7 \%$ de promedio, estamos en presencia de un sector privado que, a lo largo del periodo, apenas supera los niveles de inversión en la mejora del equipo depreciado ${ }^{43}$. Por otro lado, esta dimensión tampoco se eleva en la fase de mayor rentabilidad acontecida entre fines de la década de 1930 y la primera mitad de la década de 1940. Así, entre 1940 y 1950 la inversión global de la economía se mantiene en magnitudes de un $10,3 \%$ de promedio, contribuyendo el sector privado, de forma notoria, por debajo de la rentabilidad obtenida ${ }^{44}$. A diferencia de la visión que liga a la moderada inversión durante la ISI con la persistencia de la inflación, esta se ubica en magnitudes inferiores con respecto a las conocidas desde 1953 en adelante. Estos elementos se relacionan con lo sugerido por distintos autores acerca de la existencia de un empresariado cauto, de características más bien rentistas, renuente a tomar riesgos. En un marco protegido de la competencia externa e interna -concentración económica-, con niveles impositivos moderados a lo menos hasta 1964, el gran empresariado se aboca a satisfacer una demanda doméstica conocida privilegiando un accionar de corto plazo ${ }^{45}$. En el monetarismo, con un papel protagónico del mercado en la asignación de recursos, la inversión en capital fijo permanecerá en niveles semejantes a la etapa difícil de la ISI (véase gráfico 6). Por otro lado, la elevada rentabilidad financiera captada hacia 1988 se condice con el alza de la inversión en la fase final del neoliberalismo postcrisis económica de 1982-1983. Esta no superará los 20,5 puntos porcentuales, con un ROE de $32,8 \%$.

\section{Conclusiones}

La evolución de la rentabilidad financiera de los grupos empresariales chilenos entre 1938 y 1988 sitúa el análisis en el escenario de la economía chilena. El resultado obtenido nos sugiere una relación positiva entre el ROE y el tamaño del mercado. En fases de la economía con una tendencia al equilibrio entre las principales variables macroeconómicas, junto con mercados domésticos e internacionales en expansión, se aprecia un aumento de la rentabilidad financiera. A su vez, se constata que los mercados concentrados no aseguran la obtención de una elevada rentabilidad mediante el alza de precios, como tampoco lo garantiza la expansión de los grupos y la diversificación a través de la absorción de empresas. En economías de escasa innovación tecnológica y moderada produc-

\footnotetext{
${ }^{43}$ Cálculos realizados a partir de Díaz et al. (2016). Sobre la magnitud de la inversión pública, véase Muñoz (2001) y Ramos (1972).

${ }^{44}$ A partir de Díaz et al. (2016).

45 Palma (2010) subraya la tendencia a una moderada inversión como parte del estilo tradicional del capitalismo latinoamericano, en donde el empresariado disfruta de subsidios y barreras de entrada proveídas por el Estado. A diferencia de países como Corea del Sur, el Estado no introduce compulsiones o metas con respecto al desempeño productivo e inversor. Véase, además, Amsden (2001, 1992).
}

tividad la rentabilidad requiere de un escenario macroeconómico que posibilite captar el incremento de la demanda en los mercados domésticos para modelos de industrialización sustitutiva hacia adentro, y del mercado internacional, junto a condiciones cambiarias favorables, en esquemas económicos orientados a la venta de productos básicos al exterior. De este modo, el comportamiento de la rentabilidad a lo largo de modelos económicos disímiles como los representados por la ISI y el neoliberalismo, se relaciona con las vicisitudes de la demanda interna y externa.

En 1938, el impulso del avance industrial en mercados en proceso de sustitución de importaciones, junto con el resultado favorable de las exportaciones netas, conducirá a unas rentabilidades solo superadas en la fase de recuperación de la crisis de la deuda externa, registrada a fines de la década de 1980. Desde mediados de la década de 1950, en los inicios de la etapa difícil de la ISI, esta se llevará a cabo en un entorno económico caracterizado por la cobertura de los mercados que sustituyen importaciones en los bienes de consumo final e intermedios. En esta etapa, debido a la presencia de mercados saturados por producción doméstica, comenzará a restringirse el efecto de la demanda interna, cuestión que incidirá en el descenso de la rentabilidad. Desde el lado de la demanda internacional, en una economía semicerrada al exterior, la rentabilidad financiera de los grupos económicos no podrá ser sustentada por unas exportaciones netas decrecientes.

Entre 1974 y la crisis financiera de 1982-1983, la recesión del mercado interno cumplirá una función similar con respecto a la demanda que la saturación de los mercados en la fase difícil del esquema industrializador. En el monetarismo, con un mercado interno deprimido a raíz de las drásticas políticas de ajuste inflacionario, acontecerá un ciclo recesivo caracterizado por el descenso de la demanda doméstica, captada en la evolución negativa de los salarios reales y el empleo. Así, en 1978 la rentabilidad de los grupos será inferior a la obtenida en las postrimerías de la industrialización sustitutiva de importaciones. Más adelante, en el marco de la recuperación de la crisis financiera de 1982-1983, los grupos económicos serán conminados a orientarse hacia el mercado externo, posicionándose en el segmento de exportaciones no tradicionales; la rentabilidad se incrementará de forma abrupta, llegando en 1988 al nivel más alto de la serie. Desde ese entonces, grupos como Angelini, Luksic y Matte continúan situándose entre los mayores del país.

\section{Fuentes y publicaciones oficiales}

Asociación Comercial Sirio-Palestina, 1937. Industrias de las colectividades de habla árabe en Chile. Imprenta y Litografía Universo, Santiago de Chile.

Banco Central de Chile, 2001. Indicadores económicos y sociales de Chile 1960-2000. Banco Central de Chile, Santiago de Chile.

Banco Sudamericano, 1950-1968. Memorias y Balances. Santiago de Chile.

Bolsa de Comercio de Santiago, 1988. Reseñas de Valores Bursátiles. Departamento de Estadísticas y Estudios Económicos, Santiago de Chile.

Bolsa de Comercio de Santiago, 1978. Reseñas de Valores Bursátiles. Departamento de Estadísticas y Estudios Económicos, Santiago de Chile. 
Bolsa de Comercio de Santiago, 1970. Reseñas de Valores Bursátiles. Departamento de Estadísticas y Estudios Económicos, Santiago de Chile.

Bolsa de Comercio de Santiago, 1959. Reseñas de Valores Bursátiles. Departamento de Estadísticas y Estudios económicos, Santiago de Chile.

Bolsa de Comercio de Santiago, 1958. Reseñas de Valores Bursátiles. Departamento de Estadísticas y Estudios Económicos, Santiago de Chile.

Bolsa de Comercio de Santiago, 1938. Precios, diciembre, año 6, n.․ 298, Santiago de Chile.

Compañía Carbonífera e Industrial de Lota, 1944-1970. Memorias y Balances. Santiago de Chile.

Compañía Carbonífera e Industrial de Lota, 1938. 18. Memoria y balance general. Santiago de Chile.

Compañía Cemento Melón, 1924-1994. Memorias y Balances. Santiago de Chile.

Compañía Cervecerías Unidas, 1920-1988. Memorias y Balances. Santiago de Chile.

Compañía Distribuidora Nacional, 1967-1981. Memorias y

Balances. Santiago de Chile.

Compañía Industrial, 1969-1993. Memorias y Balances. Santiago de Chile.

Compañía Industrial, 1938. Memoria legal y nómina de Accionistas. Santiago de Chile.

Compañía Manufacturera de Papeles y Cartones, 1938. Memoria legal y nómina de accionistas. Santiago de Chile.

Compañía de petróleos de Chile, 1935-1990. Memorias y Balances. Santiago de Chile.

Compañía Refinería de Azúcar Viña del Mar CRAV, 1925-

1981. Memorias y Balances. Santiago de Chile.

Compañía de Seguros La Chilena Consolidada, 1900-1984.

Memorias y Balances. Santiago de Chile.

Compañía Sudamericana de Vapores, 1924-1993. Memorias y Balances. Santiago de Chile.

Colección Estrategia, 1997. Empresarios en la historia. Santiago de Chile: Editorial Gestión.

Dirección General de Impuestos Internos, 1939. Seguros e Impuestos, 11 (123). Santiago de Chile.

Ediciones Punto Final, 1967. Revista Punto Final, 2 (41). Santiago de Chile.

Empresa Periodística Editores, 1944. Diccionario biográfico de Chile. Editorial la Salle, Santiago de Chile.

Eperva, 1955-1988. Memorias y Balances. Santiago de Chile. Forestal Quiñenco, 1956-1973. Memorias y Balances. Santiago de Chile.

Instituto de Organización y Administración de Empresas, 1962. El financiamiento de la industria en Chile. INSORA, Santiago de Chile.

Molinos y Fideos Lucchetti, 1944-1994. Memorias y Balances. Santiago de Chile.

The New York Times, 1958. Chilean industrialist, September 6, p. 8.

Sociedad Explotadora Tierra del Fuego, 1955-1970. Memorias y Balances. Santiago de Chile.

Sociedad de Fomento Fabril, 1938a. Revista Industrial, SOFO$F A$, varios números. Santiago de Chile.

Sociedad de Fomento Fabril, 1938b. Rol de Industriales de Chile. SOFOFA, Santiago deCchile.

Sociedad de Fomento Fabril, 1935. Boletín SOFOFA, 52. Santiago de Chile.
Sociedad Ganadera Laguna Blanca, 1924-1978. Memoria legal y nómina de accionistas. Santiago de Chile.

Sociedad de Inversiones José Miguel Carrera, 1966-1983. Memorias y Balances. Santiago de Chile.

Superintendencia de Valores y Seguros de Chile, 1988. Circular Interna, n. 766 (15 de enero); n. ${ }^{\circ} 790$ (7 de abril). Santiago de Chile.

Yarur Manufacturas de Algodón, 1940-1958. Memorias y Balances. Santiago de Chile.

\section{Bibliografía}

Amsden, A., 2001. The Rise of the Rest: Challenges to the West from Late-Industrializing Economies. Oxford University Press, Oxford.

Amsden, A., 1992. Corea: un proceso exitoso de industrialización tardía. Editorial Norma, Bogotá.

Astorga, P., Bergés, A. y Fitzgerald, V., 2005. Endogenous growth and exogenous shocks in Latin America during the twentieth century. Discussion Papers in Economic and Social History, 57. University of Oxford, Department of Economics, Oxford.

Barbero, M. I., 2011. Los grupos económicos en la Argentina: una perspectiva de largo plazo (siglos xIx y xx). En: Jones, G. y Lluch, A. (eds.). El impacto histórico de la globalización en Argentina y Chile. Empresas y Empresarios, Temas, Buenos Aires.

Basualdo, E., 2006. Estudios de historia económica argentina. FLACSO, Buenos Aires.

Bértola, L. y Ocampo, J., 2013. El desarrollo económico de América Latina desde la Independencia. Fondo de Cultura Económica, México.

Beyer, H., 1988. La privatización de la distribución de energía eléctrica: el caso de Chilectra Metropolitana. Estudios Públicos, 32, 1-30.

Brandenburg, F., 1964. The Development of Latin American Private Enterprise. National Planning Association, Washington D. C.

Cademártori, J., 1970. la economía chilena. Editorial Universitaria, Santiago de Chile.

Carmona, E., 2002. Los dueños de Chile. Editorial la Huella, Santiago de Chile.

Carrera, J., 2007. La formación económica de la sociedad argentina: renta agraria, ganancia industrial y deuda externa 1882-2004. Imago Mundi, Buenos Aires.

Cassis, Y., Colli, A. y Schröter, H., 2016. The Performance of European Business in the Twentieth Century. Oxford University Press, Oxford.

Claessens, S., Djankov, S. y Klapper, L., 2000. The role and functioning of business groups in East Asia and Chile. Abante, 3, 97-107.

Comisión Económica para América Latina y el Caribe, 1996. Quince años de desempeño económico, América Latina y el Caribe, 1980-1995. Naciones Unidas, Santiago de Chile.

Comisión Económica para América Latina y el Caribe, 1962. La industria textil en América Latina: Chile. CEPAL, Santiago de Chile.

Colpan, A. y Hikino, T., 2016. Business Groups in the West: The Evolutionary Dynamics of Big Business. Oxford University press, Oxford.

Corporación de Fomento de la Producción, 1966. El desarrollo industrial de Chile. CORFO, Santiago de Chile.

Cuesta, M. y Newland, C., 2015. Una Historia empresarial argentina a través de la evolución del patrimonio y utilidades de tres compañías: Bunge y Born, Mercado Central Frutos, y Garovaglio y Zorraquín (1926-1955). XI Congreso Brasilero de Historia Económica.

Dahse, F., 1979. El mapa de la extrema riqueza. Santiago de Chile, Editorial Aconcagua.

Díaz-Alejandro, C., 1985. Good-bye financial repression, hello financial crash. Journal of Development Studies, 19, 1-24.

Díaz, J., Lüders, R. y Wagner, G., 2016. Chile 1810-2010, la república en cifras, historical statistics. Ediciones Universidad Católica de Chile, Santiago de Chile.

Díaz, J., Lüders, R. y Wagner, G., 2010. La república en cifras. Pontificia Universidad Católica de Chile, Santiago de Chile.

Fazio, H., 2005. Mapa de la extrema riqueza al año 2005. Editorial LOM, Santiago de Chile.

Fazio, H., 2000. La transnacionalización de la economía chilena: mapa de la extrema riqueza al año 2000. Editorial LOM, Santiago de Chile.

Fazio, H., 1997. Mapa actual de la extrema riqueza en Chile. Editorial LOM, Santiago de Chile.

Federal Reserve, 2018. Global price of coal, Australia, U.S. dollars per metric ton. (Data Base), Saint Louis, USA.

Fernández Gilberto, A., 2000. América Latina: el debate sobre los nuevos grupos económicos y conglomerados industriales después de la reestructuración 
neoliberal. Revista Europea de Estudios Latinoamericanos y del Caribe, 69, 97-108.

Fernández, P., Lluch, A. y Barbero, M. I. (eds.), 2015. Familias empresarias y grandes empresas familiares en América Latina y España: una visión de largo plazo. Fundación BBVA, Bilbao, España.

Figueroa, V., 1925. Diccionario histórico y biográfico de Chile 1800-1925. Imprenta y Litografía la Ilustración, Santiago de Chile.

Fitzgerald, V., 1998. La CEPAL y la teoría de la industrialización. Revista de la CEPAL, número extraordinario, 47-63.

Ffrench-Davis, R., 2008. Chile entre el neoliberalismo y el crecimiento con equidad, reformas y políticas económicas desde 1973. JC Sáez, Santiago de Chile.

Ffrench-Davis, R. y Stallings, B., 2001. Reformas, crecimiento y políticas sociales en Chile desde 1973. LOM-CEPAL, Santiago de Chile.

Fuentes, L., 1997. Grandes grupos económicos en Chile y los modelos de propiedad en otros países. Editorial Dolmen, Santiago de Chile.

Garretón, O. y Cisternas, J., 1970. Algunas características del proceso de toma de decisiones en la gran empresa chilena: la dinámica de la concentración. Corporación de Fomento de la Producción, Santiago de Chile.

Gasic, G., 1971. Concentración, entrelazamiento y descentralización en la industria manufacturera. CESO, Universidad de Chile, Santiago de Chile.

Gobierno de Chile, 1974. Decreto Ley n.ํ 824, Diario Oficial, 31 de diciembre de 1974, Santiago de Chile.

Guillén, M., 2001. The Limits of Convergence, Globalization and Organizational Change in Argentina, South Korea, and Spain. Princeton University Press, Princeton.

Hachette, D. y Lüders, R., 1992. La privatización en Chile. Centro Internacional para el Desarrollo Económico, Santiago de Chile.

Haindl, E., 2008. Chile y su desarrollo económico. Editorial Andrés Bello, Santiago de Chile.

Islas, G., 2011. Gobierno corporativo y estructura de propiedad en Chile: 18542005. En: Lluch, A. y Jones, G. (eds.). El impacto histórico de la globalización en la Argentina y Chile. Temas, Buenos Aires.

Jadresic, E., 1986. Evolución del empleo y desempleo en Chile, 1970-1985. Series anuales y trimestrales. Colección Estudios CIEPLAN, 20, 147-193.

Jeftanovic, P., 1979. El mercado de capitales en Chile. Departamento de Economía, Universidad de Chile, Santiago de Chile.

Khanna, T. y Yafeh, Y., 2005. Business groups in emerging markets: paragons or parasites. Harvard Business Review, Harvard, Mass.

Khanna, T. y Palepu, K., 2000. The future of business groups in emerging markets: long-run evidence from Chile. Academic of Management Journal, 43 (3), 268-285.

Kirsch, H., 1977. Industrial Development in a Traditional Society: The Conflict of Entrepreneurship and Modernization in Chile. University of Florida Press, Gainesville, Florida, USA.

Lagos, R., 1960. La concentración del poder económico: su teoría, y realidad chilena. Editorial del Pacífico, Santiago de Chile.

Landerretche, O., 1983. Inflation and Sociopolitical Conflict in Chile 1955-1970. Phd thesis, Oxford Univertsity, Oxford.

Lefort, F. y Walker, E., 2000. The effects of economic and political shocks on corporate governance systems in Chile. Abante, 2 (2), 183-206.

Lefort, F. y Walker, E., 2004. The effect of corporate governance on company market valuation and payout policy in Chile. Business School, Pontificia Universidad Católica de Chile. Santiago de Chile.

Maito, E., 2016. Distribución del ingreso, rotación del capital y niveles de rentabilidad. Economía: Teoría y Práctica. 45, 169-206.

Maito, E., 2012. La tasa de ganancia en Chile, 1986-2009. Quintas Jornadas de Economía Crítica. Universidad de Buenos Aires, Buenos Aires.

Mamalakis, M., 1976. The Growth and Structure of the Chilean Economy: from Independence to Allende. Yale University Press, New Haven, USA.

Marín, G. y Rozas, P., 1988. Los grupos transnacionales y la crisis: el caso chileno. Editorial Nueva América, Santiago de Chile.

Mariña, A. y Moseley, F., 2000. The rate of profit in the postwar Mexican economy, 1950-1993. En: Baiman, R., Boushey, H. y Saunders, D. (eds.). Political Economy and Contemporary Capitalism. M. E. Sharpe, New York.

Martínez, J., 2015. Grandes familias empresarias en Chile: sus características y aportes al país (1830-2012). En: Fernández, P., Lluch, A. y Barbero, M. I. (eds.). Familias empresarias y grandes empresas familiares en América Latina y España: una visión de largo plazo. Fundación BBVA, Bilbao.

Martinic, M., 2001. Menéndez y Braun prohombres patagónicos. La Prensa Austral, Magallanes, Chile.

Meller, P., 2007. Un siglo de economía política chilena (1890-1990). Editorial Andrés Bello, Santiago de Chile.
Monckeberg, M., 2002. El saqueo de los grupos económicos al Estado chileno. Ediciones B, Santiago de Chile.

Montero, C., 1997. La revolución empresarial chilena. CIEPLAN-Dolmen Ediciones, Santiago de Chile.

Muñoz, O., 2001. Esperanzas y frustraciones con la industrialización en Chile: una visión de largo plazo. En: Milet, P. (ed.). Estabilidad, crisis y organización de la política: lecciones de medio siglo de historia chilena. Facultad Latinoamericana de Ciencias Sociales, Chile.

Muñoz, O., 1995. Los inesperados caminos de la modernización económica. Editorial Universidad de Santiago de Chile, Santiago de Chile.

Muñoz, O., 1968. Crecimiento industrial de Chile: 1914-1965. Instituto de Economía, Universidad de Chile, Santiago de Chile.

Nazer, R., Llorca-Jaña, M. y Navarrete- Montalvo, J., 2017. The Cousiño-Goyenechea family (1810-1940): rise and fall of a Chilean family business. Atenea. 516, 49-67.

Nazer, R., 1993. José Tomás Urmeneta: un empresario del siglo xix. Centro de Investigaciones Barros Arana, Dirección de Bibliotecas Archivos y Museos, Santiago de Chile.

Palma, J. G., 2010. Why has productivity growth stagnated in most Latin American countries since the neo-liberal reforms? Cambridge Working Papers in Economic. Faculty of Economics, Cambridge University, Cambridge.

Paredes, R. y Sánchez, J. M., 1996. Grupos económicos y desarrollo: el caso de Chile. Documento de Trabajo, Universidad de Chile, Santiago de Chile.

Pinto, A., 1973. Chile, un caso de desarrollo frustrado. Editorial Universitaria, Santiago de Chile.

Ramírez, J., 1939. Anuario guía de las sociedades anónimas. Imprenta Diario La Nación, Santiago de Chile.

Ramos, S., 1972. Chile ¿una economía de transición? CESO-Universidad de Chile, Editorial Prensa Latinoamericana, Santiago de Chile.

Reyes, N., 2015. Salarios agrícolas durante la industrialización en Chile: factores económicos e institucionales. Estudios de Economía, 42 (2), 121-141.

Rodríguez, L., 1989. Rentabilidad económica y crisis industrial. Papeles de Economía Española, 39, 356-375.

Ross Schneider, B., 2013. Hierarchical Capitalism in Latin America: Business, Labor, and the Challenge of Equitable Development. Cambridge University Press, New York.

Sanfuentes, A., 1984. Los grupos económicos: control y políticas. CIEPLAN, Colección Estudios, 15, 131-170.

Sanfuentes, A., 1964. La influencia de los árabes en el desarrollo económico de Chile. Memoria, Facultad de Ciencias Económicas y Administrativas, Universidad de Chile, Santiago de Chile.

Salvaj, E. y Couyoumdjian, J. P., 2016. Interlocked business groups and the state in Chile (1970-2010). Business History, 58, 129-148.

Salvaj, E. y Lluch, A., 2012. Estudio comparativo del capitalismo argentino y chileno: un análisis desde las redes de directorio a fines del modelo sustitutivo de importaciones. Redes- Revista Hispana para el Análisis de Redes Sociales, 23 (2), 43-79

Santarcángelo, J., 2012. Concentración, rentabilidad y extranjerización en Argentina: un estudio de la cúpula empresaria. Ensayos de Economía, 22 (40), 39-59.

Sapelli, C., 2002. Concentración y grupos económicos en Chile. Estudios Públicos, $88,67-95$.

Shaikh, A., 2016. Capitalism: Competition, Conflict, Crises, Oxford University Press, Oxford.

Sunkel, O., 2011. El presente como historia: dos siglos de cambio y frustración en Chile. Catalonia, Santiago de Chile.

Tafunell, X., 2000. La rentabilidad financiera de la empresa española, 1880-1981: una estimación en perspectiva sectorial. Revista de Historia Industrial, 18, 71-112.

Thorp, R., 1998. Progreso, pobreza y exclusión: una historia económica de América Latina en el siglo xx. Unión Europea-Banco Interamericano de Desarrollo, Bruselas.

Vial, G., 2009. Agustín Edwards Mac-Clure: periodista, diplomático y político: los cuarenta primeros años del siglo xx chileno. El Mercurio-Aguilar, Santiago de Chile.

Yáñez, C., y Garrido-Lepe, M., 2017. El tercer ciclo del carbón en Chile de 1973 a 2013: del climaterio al rejuvenecimiento. América Latina en la Historia Económica, 24 (3), 224-258.

Yáñez, C. y Garrido-Lepe, M., 2015. El consumo de carbón en Chile entre 19331960: transición energética y cambio estructural. Revista Uruguaya de Historia Económica, 5 (8), 76-95. 


\section{APÉNDICE I}

Rentabilidad financiera grupos económicos según corte temporal

\begin{tabular}{|c|c|c|c|c|}
\hline \multicolumn{3}{|c|}{ ISI } & \multicolumn{2}{|c|}{ Neoliberalismo } \\
\hline 1938 & 1958 & 1970 & 1978 & 1988 \\
\hline $\mathrm{MMB}^{46}$ & MATTE & MATTE & CRUZAT-L. ${ }^{47}$ & ANGELINI \\
\hline agropecuario & papel, celulosa & $\begin{array}{l}\text { papel, celulosa } \\
\text { M.construcción }\end{array}$ & conglomerado & $\begin{array}{c}\text { pesca } \\
\text { combustible }\end{array}$ \\
\hline 13,1 & 4,5 & 9,6 & 2,5 & 30,8 \\
\hline COSATÁN & EDWARDS & $\mathrm{BHC}$ & VIAL (BHC) & MATTE \\
\hline salitre & alimentos, financiero & $\begin{array}{l}\text { banca } \\
\text { metalurgia }\end{array}$ & conglomerado & $\begin{array}{l}\text { papel, celulosa } \\
\text { minero }\end{array}$ \\
\hline 6,2 & 15,9 & 7,9 & 8,0 & 23,7 \\
\hline COUSIÑO & MMB & EDWARDS & MATTE & CAP \\
\hline carbón & agropecuario & alimentos, financiero & $\begin{array}{c}\text { papel, } \\
\text { celulosa }\end{array}$ & acero \\
\hline 5,3 & 33,6 & 9,1 & 3,7 & 43,2 \\
\hline EDWARDS & CLAUDE & LUKSIC & LUKSIC & LUKSIC \\
\hline alimentos financiero & carbón & carbón & conglomerado & cerveza, minería \\
\hline 16,2 & 15,9 & 4,8 & 8,4 & 73,5 \\
\hline MATTE & COUSIÑO & MENÉNDEZ & ANGELINI & ENERSIS \\
\hline papel & carbón & agropecuario & $\begin{array}{l}\text { pesca, } \\
\text { madera }\end{array}$ & suministro electricidad \\
\hline 9,9 & 13,9 & 2,9 & 11,8 & 11,1 \\
\hline YARUR & YARUR & YARUR BANNA & YARUR BANNA & BANCO DE CHILE \\
\hline textil & textil & textil & textil & Banca \\
\hline 31,5 & 7,3 & 2,4 & 7,4 & 23,5 \\
\hline \multirow{3}{*}{$\begin{array}{c}\text { KÜPFER } \\
\text { fundiciones }\end{array}$} & COSATÁN & SAID & EDWARDS & CLARO \\
\hline & salitre & textil & financiero & naviero \\
\hline & 4,3 & 7,3 & 0,08 & 30,6 \\
\hline \multirow{3}{*}{$\mathrm{s} / \mathrm{d}$} & SAID & ANGELINI & HOCHSCHILD & LECAROS \\
\hline & textil & pesca, madera & minería & pesca \\
\hline & 6,9 & 9,5 & 1,8 & 43,5 \\
\hline
\end{tabular}

Cuadro A.1. Rentabilidad financiera según corte temporal y sector (es) predominante (s). Ordenados según tamaño.

Fuente: fuentes y publicaciones oficiales; Figueroa (1925); Ramírez (1939); Lagos (1960); Sanfuentes (1964); Garretón y Cisternas (1970); Dahse (1979); Beyer (1988); Monckeberg (2000); Martinic (2001); Carmona (2002); Vial (2009).

\footnotetext{
${ }^{46}$ Menéndez, Montes, Braun.

${ }_{47}$ Cruzat-Larraín.
} 
Empresas consideradas para el cálculo de la rentabilidad financiera de cada grupo económico según corte temporal (1938-1988)

\begin{tabular}{|c|c|c|c|c|c|}
\hline Grupo & Empresa & ROE & Rama/Negocio & Capital y Reservas (\$) & \% C y R Total ${ }^{48}$ \\
\hline \multirow{3}{*}{ MMB } & T. del Fuego & 21,7 & Agropecuario & 240.378 .740 & \\
\hline & M. Behety & 12,1 & Ganadero & 106.653.273 & \\
\hline & Sara Braun & 5,5 & Ganadero & 66.342 .620 & $77,1 \%$ \\
\hline \multirow{2}{*}{ Cosatán } & Tarapacá & 4,3 & Salitrero & 381.416 .660 & \multirow{2}{*}{$100 \%$} \\
\hline & Tal Tal & 8,1 & Salitrero & 11.719 .560 & \\
\hline \multirow{3}{*}{ Cousiño } & Lota S.A. & 5,7 & Carbón & 330.570 .305 & \\
\hline & Renta Cousiño & 5,0 & Inmobiliario & 53.727 .735 & \\
\hline & Cerámica 49 & $\mathrm{~s} / \mathrm{d}$ & Cerámica & $s / d$ & $100 \%$ \\
\hline \multirow{3}{*}{ Edwards } & CRAV & 12,5 & Azúcar & 171.220 .093 & \\
\hline & $\mathrm{CCU}$ & 32,0 & Cervecero & 91.814 .602 & \\
\hline & Bco. Edwards & 4,1 & Banca Comercial & 39.350 .672 & $79,4 \%$ \\
\hline \multirow{3}{*}{ Matte } & CMPC & 15,2 & Papel & 122.794 .155 & \\
\hline & Renta Urbana & 4,1 & Inmobiliario & 66.732 .417 & \\
\hline & Sederías & 10,4 & Textil & 5.739 .168 & $94,1 \%$ \\
\hline Yarur & Yarur S.A. & 31,7 & Textil & $80.539 .000^{50}$ & $85,4 \%$ \\
\hline
\end{tabular}

Cuadro A.2. Rentabilidad financiera (ROE), tres mayores empresas grupos económicos, unidades ordenadas según tamaño, $1938^{51}$.

Fuente: Asociación Comercial Sirio-Palestina (1937); Bolsa de Comercio de Santiago (1938); Precios (1938); Carmona, E. (2002); Compañía Carbonífera e Industrial de Lota (1938); Compañía Cemento Melón (1924-1994); Compañía Cervecerías Unidas (1920-1988); Compañía Industrial (1938); Compañía Manufacturera de Papeles y Cartones (1938); Compañía de Petróleos de Chile (1935-1990); Compañía Refinería de Azúcar Viña del Mar (1925-1981); Compañía de Seguros La Chilena Consolidada (1900-1984); Compañía Sudamericana de Vapores (1924-1993); Colección Estrategia (1997); Dirección General de Impuestos Internos (1939); Empresa Periodística Editores (1944); Diccionario Biográfico de Chile; Figueroa (1925); Martinic (2001); Molinos y Fideos Lucchetti (1944-1994); The New York Times (1958); Ramírez (1939); Revista Punto Final (1967); Sanfuentes (1964); Sociedad Explotadora Tierra del Fuego (1955-1970); Sociedad de Fomento Fabril (a) (1938); Sociedad de Fomento Fabril (b) (1938); Sociedad de Fomento Fabril (1935); Sociedad Ganadera Laguna Blanca (1924-1978); Vial (2009); Yarur Manufacturas de Algodón (1940-1958).

\footnotetext{
${ }_{48}$ Porcentaje acumulativo del capital y reservas de las tres mayores empresas del grupo en relación con el total del capital y reservas del grupo.

49 Valor incluido en Lota.

${ }^{50}$ Capital y reservas correspondiente a 1941. Se calcula el porcentaje captado de Yarur, sumando las dos unidades que componen el grupo hacia 1938, la textil Yarur y el Bco. de Crédito e Inversiones, del cual se dispone del valor de su capital y reservas, no de sus utilidades netas en el periodo, por lo que no se efectúa un cálculo o aproximación acerca de su rentabilidad ROE.

${ }^{51}$ No ha sido posible efectuar un cálculo directo de la rentabilidad de Yarur. En esta oportunidad, se efectúa una aproximación a su valor en 1938 a partir del promedio de la rentabilidad financiera de tres de las mayores unidades textiles en 1934, Paños Tomé $(21,9)$, Paños Bellavista $(22,5)$ y Paños de Concepción (17,8), con un promedio de 20,7. La rentabilidad obtenida por Yarur en 1942 asciende a 42,8. De este modo, al promediar la rentabilidad de 1942 y el promedio de las tres grandes unidades en 1938, consideramos viable estimar para el año 1938 una rentabilidad financiera de la empresa Yarur de 31,7. Véase, Memorias y Balances Yarur (1941); Sanfuentes (1964).
} 


\begin{tabular}{|c|c|c|c|c|c|}
\hline Grupo & Empresa & ROE & Rama/Negocio & Capital y Reservas (\$) & \% C y R Total \\
\hline \multirow{3}{*}{ Matte } & СMPC & 6,9 & Papel & 18.908 .663 & \\
\hline & C. Melón & 4,3 & Cemento & 18.731.167 & \\
\hline & Renta Urbana & 2,4 & Inmobiliario & 8.460 .523 & $82,4 \%$ \\
\hline \multirow{3}{*}{ Edwards } & $\mathrm{CCU}$ & 7,4 & Cervecero & 21.426.293 & \\
\hline & Seguros Chile & 3,2 & Seguros & 5.432 .921 & \\
\hline & CRAV & 37,3 & Azúcar & 3.097.167 & $75,4 \%$ \\
\hline \multirow{3}{*}{ MMB } & T. del Fuego & 17,4 & Ganadería & 11.894 .740 & \\
\hline & Interoceánica & 45,0 & Naviero & 4.155 .368 & \\
\hline & Lagu. Blanca & 38,6 & Agrícola & 1.102 .670 & $72,1 \%$ \\
\hline \multirow{2}{*}{ Claude } & Schwager & 1,2 & Carbonífero & 23.347 .728 & \\
\hline & Quiñenco & 30,7 & Agrícola & 231.104 & $99,9 \%$ \\
\hline \multirow{3}{*}{ Cousiño } & Lota & 8,6 & Carbonífero & 5.793 .360 & \\
\hline & Naviera Arauco & 15,6 & Naviero & 801.946 & \\
\hline & Renta Cousiño & 17,6 & Inmobiliario & 639.360 & $63,8 \%$ \\
\hline \multirow{3}{*}{ Yarur } & Yarur M.A. & 1,7 & Textil & 5.310 .432 & \\
\hline & Caupolicán & 5,8 & Textil & 3.445 .347 & \\
\hline & Bco. Crédito & 14,6 & Banca & 1.746 .000 & $92,8 \%$ \\
\hline \multirow{3}{*}{ COSATÁN } & Tarapacá & 2,1 & Salitre & 8.777 .783 & \\
\hline & Chañaral & 6,5 & Salitre & 28.687 & \\
\hline & La Provisora & $s / d$ & Seguros & & $96,3 \%$ \\
\hline \multirow{3}{*}{ Said } & Rayón Said & 4,2 & Textil & 2.828 .280 & \\
\hline & Bco. Panam. & $s / d$ & Banca & & \\
\hline & Cerrillos & 9,6 & Metal & 848.005 & $66,9 \%$ \\
\hline
\end{tabular}

Cuadro A3. Rentabilidad financiera (ROE), tres mayores empresas grupos económicos, unidades ordenadas según tamaño, 1958.

Fuente: elaboración propia a partir de Bolsa de Comercio (1958); Bolsa de Comercio de Santiago (1959); Banco Sudamericano (1958); Cemento Melón (1958); CMPC (1958); Lagos (1960); CRAV (1958); Seguros La Chilena Consolidada (1958); Sociedad Explotadora Tierra del Fuego (1958); Sociedad Ganadera Laguna Blanca (1958); Compañía Carbonífera y Fundiciones Schwager (1958); Forestal Quiñenco (1958); Carbonífera e Industrial de Lota (1958); Yarur Manufacturas de Algodón (1958); Rayón Said (1960). 


\begin{tabular}{|c|c|c|c|c|c|}
\hline Grupo & Empresa & ROE & Rama/Negocio & Capital y Reservas Eo & \% C y R Total \\
\hline \multirow{3}{*}{ Matte } & CMPC & 6,1 & Papel & 679.944 .900 & \\
\hline & Pizarreño & 15,4 & Maderero & 119.433 .100 & \\
\hline & Sudamericano & 7,5 & Banca & 113.307 .500 & $60,5 \%$ \\
\hline \multirow{3}{*}{ BHC } & CSAV & 7,4 & Inversión & 387.748 .000 & \\
\hline & COPEC & 6,8 & Petróleo & 273.202.900 & \\
\hline & Fensa & 9,7 & Línea Blanca & 125.614 .300 & $78,3 \%$ \\
\hline \multirow{3}{*}{ Edwards } & $\mathrm{CCU}$ & 5,2 & Cervecero & 276.890 .300 & \\
\hline & Cía. Industrial & 10,2 & Jabón, Aceite & 131.167.400 & \\
\hline & CRAV & 12,0 & Azúcar & 121.045 .300 & $55,2 \%$ \\
\hline \multirow{3}{*}{ Luksic } & Lota-Schwager & 0,05 & Carbonífero & 515.777 .800 & \\
\hline & Colcura & 4,5 & Agrícola & 48.356 .100 & \\
\hline & Luchetti & 10,0 & Alimentación & 31.703 .500 & $84,6 \%$ \\
\hline \multirow{3}{*}{ Menéndez } & Tierra Fuego & 1,4 & Agropecuario & 238.446 .800 & \\
\hline & Interoceánica & 2,8 & Naviero & 51.175 .400 & \\
\hline & Laguna Blanca & 4,7 & Agrícola & 36.041 .000 & $94,2 \%$ \\
\hline \multirow{3}{*}{ Yarur } & Yarur M.A. & 3,3 & Textil & 119.332.200 & \\
\hline & Caupolicán & 0,1 & Textil & 86.014 .700 & \\
\hline & Bco. Crédito & 3,9 & Financiero & 84.557 .400 & $91,5 \%$ \\
\hline \multirow{3}{*}{ Said } & Rayón Said & 3,3 & Textil & 66.387 .100 & \\
\hline & Bco. Trabajo & 5,3 & Banca & 47.816 .300 & \\
\hline & Cerrillos & 13,4 & Metal & 37.837 .700 & $75,3 \%$ \\
\hline \multirow{3}{*}{ Angelini } & Eperva & 19,0 & Pesquero & 62.122 .800 & \\
\hline & Cholguán & 9,6 & Maderero & 48.003 .900 & \\
\hline & P. Iquique & 0,01 & Pesquero & 34.272 .300 & $78,3 \%$ \\
\hline
\end{tabular}

Cuadro A.4. Rentabilidad financiera (ROE), tres mayores empresas grupos económicos, unidades ordenadas según tamaño, 1970.

Fuente: elaboración propia a partir de Garretón y Cisternas (1970); Bolsa de Comercio de Santiago (1970); Banco Sudamericano (1970); Cemento Melón (1970); CODINA (1970); CSAV (1970); COPEC (1970); Sociedad de Inversiones José Miguel Carrera (1970); CRAV (1970); La Chilena Consolidada (1970); Cía. Industrial (1970); Forestal Quiñenco (1970); Lota-Schwager (1970); Lucchetti (1970); Sociedad Ganadera Tierra del Fuego (1970); Soc. Ganadera Laguna Blanca (1970); Sanfuentes (1964); Eperva (1970). 


\begin{tabular}{|c|c|c|c|c|c|}
\hline Grupo & Empresa & ROE & Rama/Negocio & Patrimonio (\$) & \% C y R Total \\
\hline \multirow{3}{*}{ Cruzat } & COPEC & 4,3 & Petrolero & 6.479 .760 .000 & \\
\hline & Cooperativa & $s / d$ & Inversiones & 2.955.739.098 & \\
\hline & $\mathrm{CCU}$ & 0,8 & Cervecero & 2.493.217.739 & $39,2 \%$ \\
\hline \multirow{3}{*}{ Vial } & Bco. de Chile & 14,3 & Banca & 5.146 .568 .000 & \\
\hline & INFORSA & 1,8 & Celulosa & 2.145 .768 .800 & \\
\hline & Inv. Andina & $\mathrm{s} / \mathrm{d}$ & Inversiones & 1.539 .874 .000 & $48,6 \%$ \\
\hline \multirow{3}{*}{ Matte } & CMPC & 8,1 & Papel & 6.267 .864 .400 & \\
\hline & Minera Val. Mi & 1,8 & Minería & 1.214.396.400 & \\
\hline & Pacífico Sur & 1,3 & Inversiones & 1.012 .183 .200 & $62,8 \%$ \\
\hline \multirow{3}{*}{ Luksic } & Gral. Electrici. & 1,5 & Electricidad & 2.435 .496 .000 & \\
\hline & Sudamericano & 20,0 & Banca & 1.215 .141 .200 & \\
\hline & MADECO & 3,8 & Metalurgia & 832.314 .000 & $69,4 \%$ \\
\hline \multirow{3}{*}{ Angelini } & Eperva & 15,2 & Pesquero & 1.924 .563 .200 & \\
\hline & Indo & 19,1 & Pesquero & 1.498 .537 .600 & \\
\hline & Cholguán & 1,1 & Maderero & 528.435 .600 & $70,3 \%$ \\
\hline \multirow{3}{*}{ Yarur } & Yarur & 0,8 & Textil & 1.751 .769 .600 & \\
\hline & Bco. Crédito & 14,0 & Banca & 1.332 .074 .800 & \\
\hline & Leasing & $s / d$ & Inversiones & 169.069.600 & $90,2 \%$ \\
\hline \multirow{3}{*}{ Edwards } & Inv. Chilena & 0,08 & Inversiones & 764.537.200 & \\
\hline & El Mercurio & $s / d$ & Medios comun. & 431.984 .000 & \\
\hline & La Porteña & $\mathrm{s} / \mathrm{d}$ & Inmobiliario & 367.558 .800 & $49,6 \%$ \\
\hline \multirow{3}{*}{ Hochschild } & Mantos Blan. & 2,9 & Minería & 2.150 .237 .600 & \\
\hline & Malloa & $\mathrm{s} / \mathrm{d}$ & Alimentos & 177.634 .800 & \\
\hline & Tocopilla & 0,8 & Minería & 152.684 .000 & $96,7 \%$ \\
\hline
\end{tabular}

Cuadro A.5. Rentabilidad financiera (ROE), tres mayores empresas grupos económicos, unidades ordenadas según tamaño, $1978^{52}$.

Fuente: elaboración y cálculos propios a partir de Dahse (1979); Bolsa de Comercio de Santiago (1978).

52 Los valores de la rentabilidad de este corte temporal se calculan en base al patrimonio neto. 


\begin{tabular}{|c|c|c|c|c|c|}
\hline Grupo & Empresa & ROE & Rama/ Negocio & C y R (S) & \% C y R Total \\
\hline \multirow{3}{*}{ Angelini } & COPEC & 29,5 & Petróleo & 176.720 .253 .000 & \multirow{3}{*}{$81,6 \%$} \\
\hline & Eperva & 31,7 & Pesca & 39.430 .110 .000 & \\
\hline & Indo & 31,3 & Pesca & 39.162 .728 .000 & \\
\hline \multirow{3}{*}{ Matte } & CMPC & 25,8 & Papel & 142.254 .000 .000 & \\
\hline & Pacífico Sur & 21,9 & Inversiones & 40.310.476.000 & \\
\hline & Valparaíso & 23,5 & Inversiones & 49.060 .880 .000 & $80,6 \%$ \\
\hline \multirow{2}{*}{ CAP } & Holding CAP & 9,5 & Siderurgia & 161.788 .198 .000 & \multirow{2}{*}{$100 \%$} \\
\hline & Sabimet & 77,1 & Metalurgia & 1.167 .065 .000 & \\
\hline \multirow{3}{*}{ Luksic } & $\mathrm{CCU}$ & $108^{53}$ & Cervecero & -39.973 .396 .000 & \multirow{3}{*}{$45,3 \%$} \\
\hline & MADECO & 57,2 & Metalurgia & 11.933 .284 .000 & \\
\hline & Colcura & 2,9 & Forestal & 10.384 .866 .000 & \\
\hline \multirow{3}{*}{ ENERSIS } & Enersis & 14,9 & Electricidad & 53.190 .292 .000 & \multirow{3}{*}{$100 \%$} \\
\hline & Chilectra Metro. & 7,4 & Electricidad & 34.937 .029 .000 & \\
\hline & Diprel & $\mathrm{s} / \mathrm{d}$ & Materiales & & \\
\hline \multirow{3}{*}{ Bco. Estado } & Bco. de Chile & 22,9 & Banca & 75.804 .40990 .000 & \multirow{3}{*}{$100 \%$} \\
\hline & Leasing Andino & $s / d$ & Inversiones & 1.791 .622 .000 & \\
\hline & Tattersal & 24,1 & Comercio & 632.627 .000 & \\
\hline \multirow{3}{*}{ Claro } & CSAV & 30,5 & Naviero & 24.430 .529 .000 & \multirow{3}{*}{$85,5 \%$} \\
\hline & Cristalerías & 32,7 & Vidrio & 10.703.915.000 & \\
\hline & Marítima & 28,9 & Inversiones & 10.614 .388 .000 & \\
\hline \multirow{2}{*}{ Lecaros } & SIPSA & 43,0 & Inversiones & 14.579 .482 .000 & \multirow{2}{*}{$100 \%$} \\
\hline & COLOSO & 44,2 & Pesca & 11.427.390.000 & \\
\hline
\end{tabular}

Cuadro A.6. Rentabilidad financiera (ROE), tres mayores empresas grupos económicos, unidades ordenadas según tamaño, 1988.53

Fuente: elaboración propia a partir de Bolsa de Comercio de Santiago (1988) Superintendencia de Valores y Seguros (1988); Monckeberg (2005); Beyer (1988).

${ }^{53}$ En 1988, CCU se encuentra en ronda de acreedores. La elevada rentabilidad que presenta la sociedad se debe al reducido valor de su patrimonio neto. 


\begin{tabular}{|c|c|c|c|c|c|}
\hline Grupo & Corte temporal & IHH & Grupo & Corte temporal & IHH \\
\hline Menéndez & 1938 & 9.050 & Cruzat & 1978 & 1.236 \\
\hline Cousiño & 1938 & 10.000 & Vial & 1978 & 1.988 \\
\hline Cosatán & 1938 & 7.592 & Matte & 1978 & 1.860 \\
\hline Edwards & 1938 & 3.176 & Luksic & 1978 & 1.927 \\
\hline Matte & 1938 & 4.708 & Angelini & 1978 & 5.148 \\
\hline Yarur & 1938 & 8.698 & Yarur & 1978 & 4.302 \\
\hline Küpfer & 1938 & 10.000 & Edwards & 1978 & 2.750 \\
\hline Matte & 1958 & 2.592 & Hochschild & 1978 & 8.154 \\
\hline Edwards & 1958 & 2.874 & Angelini & 1988 & 4.355 \\
\hline Menéndez & 1958 & 5.128 & Matte & 1988 & 5.174 \\
\hline Claude & 1958 & 9.608 & CAP & 1988 & 10.000 \\
\hline Cousiño & 1958 & 3.982 & Luksic & 1988 & 2.638 \\
\hline Yarur & 1958 & 6.214 & Enersis & 1988 & 5.200 \\
\hline Cosatán & 1958 & 9.414 & Bco. de Chile & 1988 & 9.222 \\
\hline Said & 1958 & 4.656 & Claro & 1988 & 3.112 \\
\hline Matte & 1970 & 2.433 & \multirow[t]{8}{*}{ Lecaros } & \multirow[t]{8}{*}{1988} & \multirow[t]{8}{*}{5.074} \\
\hline BHC & 1970 & 2.774 & & & \\
\hline Edwards & 1970 & 2.482 & & & \\
\hline Luksic & 1970 & 5.478 & & & \\
\hline Menéndez & 1970 & 6.458 & & & \\
\hline Yarur & 1970 & 5.104 & & & \\
\hline Said & 1970 & 3.382 & & & \\
\hline Angelini & 1970 & 4.872 & & & \\
\hline
\end{tabular}

Cuadro A.7. Valores Índice Herfindahl-Hirschman. Grupos económicos según corte temporal (1938-1988), ordenados según tamaño. Fuente: elaboración propia. 